Fisheries Research

March 2015, Volume 163 Pages 44-57

http://dx.doi.org/10.1016/i.fishres.2014.03.008

http://archimer.ifremer.fr/doc/00254/36511/

(c) 2014 Elsevier B.V. All rights reserved.

\title{
Determining the age of tropical tunas in the Indian Ocean from otolith microstructures
}

\author{
Sardenne Fany ${ }^{1,2}$, Dortel Emmanuelle ${ }^{3,6}$, Le Croizier Gaël ${ }^{1,2}$, Million Julien ${ }^{2}$, Labonne Maylis ${ }^{4}$, \\ Leroy Bruno ${ }^{5}$, Bodin Nathalie ${ }^{1}$, Chassot Emmanuel ${ }^{1 *}$
}

${ }^{1}$ SFA, Inst Rech Dev, IRD Ifremer UM2, UMR EME 212, Victoria, Seychelles.

2 Indian Ocean Tuna Commiss, Victoria, Seychelles.

3 Inst Rech Dev, IRD Ifremer UM2, UMR EME 212, F-34203 Sete, France.

${ }^{4}$ CNRS, UBO IRD Ifremer, Inst Rech Dev, UMR LEMAR 6539, F-29280 Plouzane, France.

${ }^{5}$ Secretariat Pacific Community, Noumea 98848, New Caledonia.

${ }^{6}$ Ifremer, France

* Corresponding author: Emmanuel Chassot, Tel.: +248 4670 307; fax: +248 4224742 ; email address : Emmanuel.Chassot@ird.fr

\begin{abstract}
:
The Indian Ocean Tuna Tagging Program (IOTTP) provided a unique opportunity to assess the viability of estimating the age of tropical tunas from the micro-structural features of otoliths. Here, we analyzed the length measurements and micro-increment counts collected for 506 sagittal otoliths, of which 343 were chemically marked with oxytetracycline, for bigeye (Thunnus obesus), skipjack (Katsuwonus pelamis), and yellowfin tuna (Thunnus albacares). Our results show that the otoliths of tropical tunas grow more slowly than the rest of the body. Our findings confirm that both yellowfin and juvenile bigeye deposit daily increments in their otoliths, though ages are underestimated for large bigeye $(>100 \mathrm{~cm})$ when derived from micro-increment counts. Our results also indicate that skipjack otoliths are not suitable for age estimations during the adult phase, as evidenced by the poor agreement between micro-increment counts and days-at-liberty. We hypothesize that the income breeding strategy of skipjack could explain the variability observed in the deposition rates. Due to their complex microstructural patterns, the reading of tropical tuna otoliths requires a degree of interpretation that can result in poor count precision and large variability in micro-increment counts, both among and within teams of readers. Age estimates were found to vary between readers, a factor which can eventually affect growth estimates and ultimately, impact on fisheries management decisions and outcomes. To address this, we recommend that reference collections of otoliths are developed, with a view to standardizing the reading process. Further, alternative methods, such as annual age estimations (as opposed to daily), and alternative structures, such as dorsal spines for skipjack, should be used to improve the accuracy of age estimations and the speed with which they can be made.
\end{abstract}




\section{Highlights}

- We confirm that yellowfin and juvenile bigeye deposit daily micro-increments in otoliths. Our results support previous findings that deposition rates in adult skipjack are highly variable. Age estimates are characterized by very low precision and strongly dependent on the reader. Variability in otolith reading can affect growth estimates. Reference collections are required to standardize the reading of tuna micro-increments.

Keywords : Daily age, Micro-increment, Mark-recapture, Oxytetracycline, Thunnus 


\section{Introduction}

Information from age structures plays a significant role in fisheries science, with fish population

models largely based on age-dependent demographic features. Worldwide, millions of otoliths are read annually to estimate fish age and provide essential information to improve the stock assessment models which underpin fisheries management (Campana and Thorrold, 2001). Otoliths

51 are commonly used because uniquely, they do not absorb calcium. However, other calcified structures, such as dorsal spines, scales, and vertebrae have also been widely used to provide annual age estimates (Panfili et al., 2002). The chronological properties of otoliths have been known since

54 the 19th century, but gained wider recognition with the seminal article by Pannella (1971). Since then, the growing demand for fish age estimates have led scientists to conduct further research in the field of sclerochronology, focusing in particular on improving the preparation, conservation, and

57 reading of otoliths (Secor et al., 1995; Panfili et al., 2002; Begg et al., 2005).

In tropical environments, it is particularly difficult to estimate fish age using otolith increments

60 (annual or seasonal) because growth cycles are not related to environmental conditions (e.g., there is less seasonal contrast in tropical waters as compared with temperate waters; Green et al., 2009). In the 1970s, the sub-seasonal patterns in the micro-structural features (i.e., micro-increments) of

63 otoliths were investigated in several tropical fish species. This research revealed that these microincrements followed a circadian rhythm which was physiologically controlled and influenced by environmental conditions (Pannella, 1971, 1974). Each micro-increment corresponds to a bipartite

66 structure which is composed of two alternating zones, an incremental (or accretion) zone and a discontinuous zone. Each zone is characterized by a distinct composition of organic and mineral fractions (Campana and Neilson, 1985; Campana, 1999). These early findings prompted the

69 significant growth in studies that used optical microscopes to investigate otolith micro-structures as a way of estimating the age and growth of tropical tunas worldwide (Table 1). Counts of micro- 
increments in sagittal otoliths were first used to estimate ages of yellowfin (Thunnus albacares;

72 YFT) and skipjack tuna (Katsuwonus pelamis; SKJ) in the Eastern Pacific Ocean (Wild and Foreman, 1980). This study validated the presence of a daily deposition rate in the otoliths of YFT (size range: $40 \mathrm{~cm}-110 \mathrm{~cm}$ fork length; $F_{L}$; i.e., the length measurement taken from the tip of the 75 snout of a fish to the fork of its tail) collected from oxytetracycline (OTC) mark-recapture experiments. SKJ, however, was found to exhibit a non-daily deposition rate. Subsequent studies conducted in the Pacific Ocean increased the number and extended the size range of fishes sampled 78 and confirmed a daily micro-increment deposition rate for YFT between $40 \mathrm{~cm}$ and $148 \mathrm{~cm} F_{L}$ (Yamanaka, 1990; Uchiyama and Struhsaker, 1981; Wild et al., 1995; Lehodey and Leroy, 1999). More recently, Hallier et al., (2005) and Schaefer and Fuller (2006) validated a daily deposition rate

81 for bigeye (T obesus; BET) sized between $44 \mathrm{~cm}$ and $95 \mathrm{~cm} F_{L}$ in the Atlantic Ocean and between $38 \mathrm{~cm}$ and $135 \mathrm{~cm} F_{L}$ in the Eastern Pacific Ocean (Table 1). For SKJ, although further research (e.g., mark-recapture and captivity experiments) were conducted, none of the results pointed to a

84 link between days-at-liberty and micro-increment counts (Table 1). There is also a growing body of literature investigating the use of annual (as opposed to daily) age structures to provide age estimates in tunas including vertebrae (Prince et al., 1985; Rodriguez-Marin et al., 2006), dorsal 87 spines (Sun et al., 2001; Lessa and Duarte-Neto, 2004), and more recently, otoliths (Farley et al., 2003; Griffiths et al., 2010; Chen et al., 2012; Shih et al., 2014; Williams et al., 2013).

90 In the Western Indian Ocean, the few studies that have dealt with age estimates of tropical tunas have had contradictory results and none have investigated the micro-increment deposition rates for YFT and BET (Table 1). Stéquert et al., (1996) was the first to establish a von Bertalanffy (1938)

93 growth curve for YFT based on otolith micro-structures. However, it resulted in an asymptotic length estimate that was inconsistent with YFT biology (i.e., $F_{L}>270 \mathrm{~cm}$ ). In addition, the growth pattern estimated for juvenile YFT $\left(F_{L}<60 \mathrm{~cm}\right)$ differed considerably from the results of an 
96 extensive analysis of length-frequency distributions which were based on purse-seine, gillnet, and longline fisheries landings (IOTC, 2005; Viera, 2005). For BET, age and growth estimates were made from micro-increment counts obtained using both an optical microscope and scanning

99 electron microscope, particularly for large fish $\left(F_{L}>120 \mathrm{~cm}\right)$ (Stéquert and Conand, 2000, 2004). Finally, micro-increment deposition rates for SKJ derived from mark-recapture experiments were found to vary greatly among individuals, suggesting that micro-increment counts are not suitable for

102 estimating the age of this species. However, this study was only based on a small, localized sample of fish $(n=8)$ collected from Maldivian waters.

105 The Indian Ocean Tuna Tagging Program (IOTTP), which began in 2004, provided a unique opportunity to improve research efforts into understanding the age and growth rates of tropical tuna. An area of particular interest was the hypothesis that micro-increment deposition occurs at a rate of 108 one per day in the otoliths of YFT, BET, and SKJ in the Indian Ocean. More than 200,000 tunas were tagged with conventional dart tags through the IOTTP and about $3 \%$ of these were also injected with a fluorescent marker that is rapidly incorporated into the otoliths (Hallier, 2008).

111 Using recovered otoliths, the main objectives of this study were to (i) estimate the frequency and consistency of micro-increment deposition in otoliths for the purposes of estimating the age of tropical tunas, (ii) assess the influence of otolith readers on micro-increment counts (i.e., how the

114 age structures are interpreted by different individuals), and finally (iii) evaluate the influence of different otolith readers on growth estimations (when they are based solely on otolith data).

\section{2. Material and Methods}

\subsection{Tuna sampling and otolith extraction}

The majority of otoliths and length data used in this study were collected through the Regional Tuna 120 Tagging Project (RTTP), the main component of the IOTTP, conducted by the Indian Ocean Tuna 
Commission (IOTC). During 2006 - 2007, approximately 160,000 tunas were tagged with dart tags. Of these, about 6,000 fish were injected with OTC, a chemical that is rapidly incorporated by the

123 fish and leaves a fluorescent mark in their calcified tissues (Wild and Foreman, 1980; Campana and Neilson, 1985) (Table S1). Depending on the size of the fish, between $1.5 \mathrm{~mL}$ and $3 \mathrm{~mL}$ of OTC were injected intramuscularly into their back (Hallier, 2008). Tag recovery operations took place

126 across the entire Indian Ocean basin between 2004 and 2013. As of September 2013, more than 22,000 tunas with reliable length and species identification records had been recovered, including 536 OTC-tagged individuals (Table S1). Most of the reported recoveries (about 85\%) were for fish

129 caught by European purse-seiners based in Victoria, Seychelles (Hallier 2008). The $F_{L}$ of recaptured tunas was measured to the nearest $0.5 \mathrm{~cm}$. Recovery positions and date information were accurately known for tags found at sea (27\% of all recoveries). Uncertainty arose, however, when a tag was

132 recovered from a purse-seiners' well as they can contain fish from multiple fishing sets. In these cases, the location and time uncertainties associated with each recapture were derived from the logbook data and well maps.

The RTTP tagging operations took place aboard two pole and line vessels, which mostly catch small- and medium-sized tunas. The tunas tagged ranged in size between $32 \mathrm{~cm}$ and $144 \mathrm{~cm} F_{L}$, 138 with 75\% measuring between $48 \mathrm{~cm}$ and $59 \mathrm{~cm} F_{L}$, and 95\% measuring $<71 \mathrm{~cm}$ (Table S1). This gear selectivity at tagging resulted in the recovery of very few small fish with reliable fork length measurements. Of the total number of tunas recovered, only $1 \%$ measured $<45 \mathrm{~cm}$ and the smallest

141 fish measured $34.7 \mathrm{~cm} F_{L}$. To complement the size range of tunas recovered by the purse seiners, an additional 40 otoliths were collected from 20 small YFT $\left(19 \mathrm{~cm}-29 \mathrm{~cm} F_{L}\right)$ and 20 small SKJ (20.5 $\mathrm{cm}-25 \mathrm{~cm} F_{L}$ ) that were caught in August 2007 in association with a fish aggregating device. This

144 device was anchored off the Indonesian coast ( $100^{\circ} \mathrm{E}$ longitude, $1.6^{\circ} \mathrm{S}$ latitude) and these fish were recovered as part of the West Sumatra Tuna Tagging Project (WSTTP; Anonymous, 2008). In 
addition, data from a further 56 non-tagged YFT collected between April 2008 and April 2009 from

147 purse-seine landings in Victoria, Seychelles were considered in this analysis. In total, we used otolith and length data obtained from 506 tunas collected between 2006 and 2012, including 343 that were OTC-marked, i.e., 142 BET (139 OTC-marked), 81 SKJ (43 OTC-marked), and 283 YFT

150 (161 OTC-marked). The majority of these fish were collected in the Western Indian Ocean (Fig. 1). The final size ranges represented in these data were $46 \mathrm{~cm}-142 \mathrm{~cm} F_{L}$ for BET, $20.5 \mathrm{~cm}-63 \mathrm{~cm}$ $F_{L}$ for SKJ, and $19 \mathrm{~cm}-153 \mathrm{~cm} F_{L}$ for YFT (Fig. S1). While we consider that the size range for

153 YFT is comprehensive (Fig. S1c), there are some data coverage issues for BET and SKJ. The final data set for BET only included eight fish $>100 \mathrm{~cm} F_{L}$ (Fig. S1a) and for SKJ, there was only one fish in the $25 \mathrm{~cm}-48 \mathrm{~cm} F_{L}$ size range (Fig. S1b).

156

After decapitation, sagittal otoliths were extracted with forceps. They were cleaned with ultra-pure water, and when necessary, ultrasound was used to remove adhering vestibular tissue. After

159 cleaning, the otoliths were stored in plastic micro-tubes for subsequent analyses. Not all of the otoliths from recaptured tunas were prepared. The main criterion for selecting which otoliths were prepared was the quality of information available for each fish. Only otoliths from fish with good

162 information (i.e., accurate dates, species identification, $F_{L}$ at tagging and recapture, and times-atliberty for OTC-marked individuals) were selected.

165 2.2. Otolith analysis

\subsubsection{Otolith preparation}

All otoliths were prepared following the same protocol used at the Laboratoire des Sciences de

168 l'Environnement Marin in Brest, France (Stéquert, 1995). For consistency, only the left sagittal otolith was used, although it has been shown that the number of micro-increments between the left and right sagitta are not statistically different for tropical tunas (Wild and Foreman, 1980). The first 
171 step in preparation was to set the otolith into a block of epoxy resin (Araldite ${ }^{\circledR} 2020$ mixed with the catalyst 2020-B). Two transversal cuts were then made either side of the nucleus to obtain an otolith section of approximately $1 \mathrm{~mm}$ thickness. This section was then attached to a glass slide using

174 Crystal Bond ${ }^{\circledR}$ thermoplastic resin, a temporary mounting adhesive that enables the section to be turned. Both sides of the section were then polished with a diamond suspension ( $3 \mu \mathrm{m}$ grit). At this stage of preparation, particular attention was paid to ensure that the nucleus was not sanded away.

177 This final otolith section (80 $\mu \mathrm{m}-100 \mu \mathrm{m}$ thickness) was then decalcified with a few drops of $10 \%$ tri-sodium ethylene diaminetetraacetic acid (EDTA) for several seconds to enhance the contrast between the micro-structural features. To reduce the risk of decalcifying the otolith too much and making it too dark to read, the EDTA reaction was monitored using an optical microscope at 400x magnification. The final otolith section was then rinsed with distilled water to finish the preparation process. Hereafter, the term “otolith” refers to a prepared otolith section.

\subsubsection{Otolith readers}

A total of seven readers analyzed the otoliths between 2008 and 2012. Although repeated counts

186 were undertaken, the number of repeats varied between preparations, according to available funds and personnel, as well as IOTC priorities (Table 2). Thus, not all otoliths were read by all readers. To assess the influence of individual readers on micro-increment counts, the seven readers were 189 grouped into four teams according to their prior experience in reading tuna otoliths (less than two years versus more than two years), the amount of training they had received from former readers, and their institute of affiliation (Table 2).

\subsubsection{Otolith measurements}

The length of the otolith section $\left(L_{O}\right)$ was measured along the counting path, from the nucleus (point 195 of original growth) to the last micro-increment deposited on the maximal growth axis. To account 
for changing growth rates with age, this measurement was taken in two linear segments $\left(L_{1}\right.$ and $\left.L_{2}\right)$, and $L_{O}$ was estimated from the sum of these two segments (Stéquert et al., 1996; Fig. 2a). $L_{O}$ measurements were completed by Teams 1-3 using an optical microscope (Olympus BX41 with 100x or 200x magnification) coupled with TNPC® 4.3 software. In addition, Team 2 also completed some readings using the easier and faster Leiss binocular and Axiovision software

201 combination which is an alternative measuring method.. In total, otolith length measurements were made for 140 BET $\left(46 \mathrm{~cm}-141.6 \mathrm{~cm} F_{L}\right)$, $63 \mathrm{SKJ}\left(20.5 \mathrm{~cm}-63 \mathrm{~cm} F_{L}\right)$, and 223 YFT $(19 \mathrm{~cm}-$ $153 \mathrm{~cm} F_{L}$ ). Of these, 155 otoliths were measured using both the microscope and the binocular, and

204 these data were used to assess the effects of the measurement method on otolith length measurements. Finally, for a small subset (eight otoliths), $L_{O}$ measurements were repeated three times to estimate measurement accuracy.

\subsubsection{Micro-increment counts}

All otoliths were randomly selected prior to reading (i.e., without any prior knowledge of how many

210 times it had been counted or its corresponding fish identification or length). Readings were completed on dry otolith sections with transmitted light, using a light microscope (Olympus BX41 with camera at 1000x magnification:10x ocular and 100x lens) and TNPC® 4.3 software. Micro-

213 increment counts were made for two different otolith sections. Measurements of Section 1, from the OTC-mark to the otolith edge $\left(I_{m}\right)$, allow for the periodicity of the deposition rate to be assessed (see section 2.3.2). Measurements of Section 2, from the nucleus to the otolith edge $\left(I_{t}\right)$, provide

216 estimates of absolute age and enable us to derive growth curves from which we can then assess the influence of the reader on growth estimation (see section 2.3.4). Counts were made on a computer screen using a manual cell-counter. Using a reading window of at least $60 \mu \mathrm{m}$ wide, micro-

219 increments were counted along the outer edge of the ventral side, following the axis of maximal growth (Fig. 2b-d). For chemically-marked otoliths, an ultraviolet light was used to detect the 
fluorescent OTC-mark. No time corrections were required for full otolith sections, as it has been

222 shown that the larvae of tropical tunas deposit their first growth micro-increment one day after hatching (Radtke, 1983; Wexler et al., 2007).

225 The interpretation of the deposition patterns observed in these otoliths was subjective. To start with, full micro-increments had to be distinguished from sub-micro-increments, which are characterized by faint and incomplete rings. In addition, overlapping micro-structures caused by irregular

228 incrementation were often observed (Fig. 2c). Finally, some otoliths presented with illegible subsections. In these instances, a micro-increment count had to be interpolated from the surrounding sub-sections (Fig. 2d). This type of interpolation has been found to be reasonable in cases where the

231 number of interpolated micro-increments is relatively small in comparison to the total microincrement count (Campana, 1992). The degree of interpretation required was found to vary in accordance with the quality of otolith preparation; however, a quality index was not available in this

234 study. Difficulties with interpretation are generally assumed to decrease as the experience level of the reader increases.

237 2.3. Statistical analyses

\subsubsection{Modeling the relationship between otolith growth and somatic growth}

For each species, otolith length $L_{O}$, was modeled as a function of $F_{L}$, with linear and non-linear power regressions, to investigate the relationship between otolith growth and somatic growth. Model parameters were estimated following the maximum likelihood approach using the "Im" and “nls” functions implemented in R (R Development Core Team 2013). Gaussian error distribution

243 and homoscedasticity hypotheses were checked using the residuals. Model selection was based on the Akaike information criterion (AIC) calculated for each model. 


\subsubsection{Modeling the deposition rate in tropical tuna otoliths}

The relationship between times-at-liberty and micro-increment counts was investigated for OTCtagged tunas based on the accuracy of the times-at-liberty. Uncertainty associated with the recapture date (expressed in days) should be $<5 \%$ of the mean time-at-liberty derived from the expected mean recapture date. A total of 116 OTC-tagged tunas BET (46 cm - $\left.141.6 \mathrm{~cm} F_{L}\right), 34 \mathrm{SKJ}(48.5 \mathrm{~cm}$ - $\left.60.2 \mathrm{~cm} F_{L}\right)$, and 112 YFT (47.9 cm - $135.4 \mathrm{~cm} F_{L}$ ) were selected. The times-at-liberty varied 252 between 3 and 1,166 days for BET, 50 and 602 days for SKJ, and 8 and 969 days for YFT. For BET and SKJ, about $90 \%$ of the otoliths analyzed were collected from tunas that spent less than one year-at-sea. For YFT, these values were more balanced, with 25\% of fish having spent more than one year-at-sea and 5\% having spent more than two years-at-sea.

For each reading team $r$, the number of $I_{m}$ micro-increments was modeled as a linear function of 258 time-at-liberty $D$, following:

$$
I_{m}=a_{r} \cdot D+b_{r}
$$

where $a$ corresponds to the pattern of deposition estimated by each team, and $b$ is an additive error

261 term that results from several factors, such as reader experience or otolith morphology. Given none of the readers had any prior information on the fish whose otoliths they were reading and the otoliths of BET and YFT are indistinguishable, the intercept $b$ was considered to be identical for

264 each of the two species for any given reading team. Model parameters were estimated using Bayesian inference as implemented in OpenBugs version 3.2.1 (Spiegelhalter et al., 2011). Gaussian error distribution and homoscedasticity hypotheses were checked using the residuals. Details on the

267 methodology used to generate prior distributions, simulations, and convergence diagnostics are available in the Supplementary Online Materials (SOM). 
For all species and every team of readers, the relationship between the standard deviation and mean number of micro-increment counts was used to determine how overall count precision varied with

273 age, i.e., how consistent micro-increment counts were between different age determinations. This relationship was based on data from a subset of otoliths which were read a minimum of six times ( $n$ = 114). The precision in age determination was then estimated for each team of readers and species

276 using the coefficient of variation (CV) of micro-increment counts averaged across fish (Chang, 1982; Campana et al., 1995). Linear regression models and non-parametric Wilcoxon matched-pairs rank tests were then used to assess the consistency of age determinations between reading teams for

279 otoliths that were read in common (Campana et al., 1995).

\subsubsection{Evaluating the reader effects on growth estimates}

282 The uncertainty associated with multiple otolith readings was modeled to estimate the true number of increments for each fish otolith. The number of increments counted for reading $l$ of otolith i $\left(I_{i, l}\right)$ was assumed to be distributed around the expected number of increments following a normal

285 distribution (Dortel et al. 2013). This number was then converted into absolute age accounting for the potential biases of each reading team based on the species-specific regression models linking $I_{m}$ and $D$ (see section 2.3.2). The conversion assumed that these relationships were valid for tuna that

288 were bigger and smaller that the specific size range of the OTC-tagged tunas considered. Somatic growth models were then fitted to the age and $F_{L}$ data using Bayesian inference to assess the influence of reading method on growth estimates determined solely from otolith data. Growth was

291 modeled using a Von Bertalanffy logK model, which allows fish to exhibit two successive and distinct growth phases over time (Eveson et al., 2004). Information on the asymptotic length parameter was provided by informative prior distributions derived from tuna size measurements

294 (see SOM). The technical details of calculating the prior distributions and the posterior estimates are described by Dortel et al., (2013). 


\section{3. Results}

\subsection{Relationship between otolith length and fish length}

For YFT, otolith length measurements were obtained from fish that represented the entire size range caught by purse seine $\left(20 \mathrm{~cm}-150 \mathrm{~cm} F_{L}\right.$ ). In contrast, only a few otolith length measurements were available for large BET ( $>100 \mathrm{~cm} F_{L}$ ) and very few measurements were collected from the 25 $\mathrm{cm}-50 \mathrm{~cm} F_{L}$ size range for SKJ (Fig. 3). The measurement method used to estimate otolith length

303 (i.e., binocular or microscope), did not affect $L_{O}$ measurements (Fig. S2). The repeated binocular measurements indicated that there was a strong consistency between the number of readings and small observation errors in $L_{O}$ (Fig. S3). The mean CV of otolith length for the eight otoliths which were measured three times was $1.5 \%$. Otolith growth in tropical tunas of the Indian Ocean was found to be strongly positive and non-linearly correlated with somatic growth, following allometric relationships. Non-linear power regressions between $F_{L}$ and $L_{O}$ were found to be significant ( $p<$

309 0.001) for all three tuna species (Fig. 3). Power regression models explained the variability in otolith growth better than linear models (i.e., the AIC was lower for each species-specific model). The allometric coefficients of the relationships were close to 0.6 and did not significantly differ

312 between species, i.e., $0.59(\mathrm{SE}=0.021)$ for BET, $0.58(\mathrm{SE}=0.023)$ for SKJ, and $0.6(\mathrm{SE}=0.013)$ for YFT. This result indicates that the otoliths in tropical tunas grow more slowly than the rest of the body.

\subsection{Frequency of deposition}

The relationship between micro-increment counts and days-at-liberty show that juvenile BET in the

318 Indian Ocean have a daily micro-increment deposition rate. For BET, the slope $a$ of the relationship between $I_{m}$ and $D$ was not found to be statistically different (i.e., very close to 1 ) for the three teams of otolith readers (Table 3). However, this relationship was strongly influenced by the proportion of 
321 juvenile BET in the data set while the relative age (i.e., time-at-liberty) of large individuals was underestimated. Micro-increment counts made by each of the three reading teams were smaller than actual times-at-liberty for $D>400$ days (which corresponds with BET $>100 \mathrm{~cm} F_{L}$; Fig. 4a). The

324 discrepancy between the observations and the regression model predictions increased with $D$, exceeding 200 days for $D>1000$ days (which corresponds with BET $>120 \mathrm{~cm} F_{L}$ ). Microincrement counts in the otoliths of adult SKJ for the times-at-liberty indicated that their deposition

327 rate during the adult phase displayed a high degree of variability and there were also differences in count values between and within the teams of readers (Fig. 4b). The slope of the regression models varied between 0.51 micro-increment per day $\left(m^{-1}\right)$ for Team 1 and $0.16-0.17 m \mathrm{~d}^{-1}$ for Teams 2 and 4 (Table 3). For YFT (size range: $50 \mathrm{~cm}-135 \mathrm{~cm} F_{L}$ ), Team 2 found that the micro-increment deposition rate was daily while Team 1 estimated the rate to be $<1 \mathrm{~m} \mathrm{~d}^{-1}$. The mean deposition rate was $0.98 \mathrm{~m} \mathrm{~d}^{-1}(\mathrm{SD}=0.03)$ for Team 2 , but significantly $<1 \mathrm{~m} \mathrm{~d}^{-1}$ (mean $=0.88$, SD =0.02) for

333 Team 1 (Table 3). In comparison to BET, no pattern in the model residuals was found for YFT, which indicated good agreement between the micro-increment counts and days-at-sea for the size range and times-at-liberty observed (Fig. 4c).

The intercept $b$, for the relationships between $I_{m}$ and $D$, represents the systematic bias in age estimates and differed between both the teams of reader and species. The least experienced Team 2,

339 had the highest bias values for the three species amongst any of the teams of readers (+7.4 microincrements for BET and YFT and +10.9 micro-increments for SKJ; Table 3). Teams 1 and 3 exhibited a small negative bias $(<1$ micro-increment), while the bias of Team 4 was +7.4 micro342 increments for SKJ.

\subsection{Reader influence on micro-increments counts}

345 Counting precision generally decreased as the age of the fish increased. The overall standard 
deviation of micro-increment counts was found to significantly increase with the mean number of micro-increment counts ( $p<0.001$; adjusted Pearson's $r=0.85$ ). This describes a typical multiplicative error associated with the reading process (Fig. S4). Counting precision was generally low and differed considerably between the teams of readers and the three species. Team 4, who read 29 SKJ otoliths, was found to be the most precise, with a CV of 5.5\% for micro-increment counts

351 (Table 4). By contrast, Team 3's readings of 137 BET otoliths, were characterized by low reproducibility, with a CV of almost 70\%. Teams 1 and 2, who read otoliths from all three species, had mean CVs of $41.3 \%$ and $20.2 \%$, respectively (Table 4). Within each team, precision also varied

354 greatly between species. For example, for Team 2, the CV for SKJ was < 10\%, but $>23 \%$ for YFT. Finally, precision also varied between individual readers for each particular species, e.g., for SKJ, CVs for each reader ranged from between 5.5\% and 70\% (Table 4). Overall, count precision did not 357 appear to be related to a particular species, but rather to the team of readers. Although no team's counting precision was very high, the less-experienced Team 2 was found to be more precise.

360 The pairwise comparisons of micro-increment counts for the otoliths that were read in common showed that there were major differences in the results of the reader teams. With the exception of BET otoliths (read by Teams 2 and 3; $p=0.41$ ), the non-parametric Wilcoxon matched-pairs rank 363 test indicated that the micro-increment count estimates significantly differed between Teams 1 and 2 and Teams 1 and 3 for BET, between Teams 2 and 4 for SKJ, and between Teams 1 and 2 for YFT $\left(p<2.10^{-5}\right)$. Although the linear regression models showed significant positive correlations between 366 the micro-increment count estimates (adjusted Pearson's $r>0.65$ ), the slope of each model was found to be significantly different than 1 (Fig. 5). For BET, there was, in general, a good agreement between the micro-increment counts $(<500)$ made between the different teams of readers (Fig 5a369 c). However, for counts between the 500 and 700 micro-increment range, Teams 2 and 3 counted more than Team 1 (Fig. 5a-b). Further complicating these differences is that within this micro- 
increment range, the estimates of Team 3 were even higher than those made by Team 2, but became

372 lower for counts $>700$ micro-increments (Fig. 5c). The highest variability in micro-increment counts was observed for SKJ otoliths, which were characterized by wide discrepancies in count estimates between Teams 2 and 4 (more than two-fold difference for several otoliths; Fig. 5d).

375 Finally, for YFT, the estimates appeared consistent between teams for micro-increment counts < 700, but Team 2 was found to count more micro-increments thereafter (Fig. 5c).

378 3.4. Reading team effect on growth curves

The absolute ages of 129 BET $\left(46 \mathrm{~cm}-141.5 \mathrm{~cm} F_{L}\right)$ and 215 YFT $\left(19 \mathrm{~cm}-152 \mathrm{~cm} F_{L}\right)$ were derived from the species-specific relationships between $I_{m}$ and $D$. No age estimation was made for

381 SKJ given the high variability observed in the micro-increment counts and the absence of a clear relationship between $I_{m}$ and $D$ (see above). The shape of the growth curve estimated from the agelength data was found to vary according to each team of readers. The growth curves estimated for

384 BET significantly differed between Team 1 and Teams 2 and 3 in the size and age range encompassed by the otolith data (Fig. 6a). The growth rate $k_{1}$, estimated from Team 1's data was found to be significantly higher than from Teams 2 and 3's data (Table S5). BET growth curves

387 derived from micro-increment counts of Teams 2 and 3 were similar for those fish aged one to four years and diverged significantly for ages greater than four years, mainly due to the lack of data for old fish. For YFT, differences in the age estimates derived between Teams 1 and 2 were not as great 390 as the differences observed between the micro-increment counts after the age conversion (which took into account the reader bias; Fig. 6b). The growth curves were not statistically different for those fish younger than two years, but they significantly differed for fish aged between 2.5 and 4.5 393 years. 


\section{Discussion}

396 The IOTTP provided a unique opportunity to test the hypothesis that there is a daily microincrement deposition rate in the three key commercial tuna species of the tropical Indian Ocean. In this program, OTC-marked YFT and BET were recovered around three years after their initial

399 tagging, which resulted in times-at-liberty that were more than twice as long as those observed in the Eastern Pacific and Atlantic Oceans (Wild et al., 1995; Hallier et al., 2005; Schaefer and Fuller, 2006). Thus, this offered a significantly longer period of time against which to validate age reading

402 estimates. Although it was impossible to fully disentangle the effects of temporal variability on micro-increment deposition rates from reading errors when relating times-at-liberty to microincrement counts, our findings show that both YFT (less than five years) and BET (less than three

405 years) deposit daily increments in their otoliths. This finding is similar to deposition rates observed in the Pacific and Atlantic Oceans. However, when an interpretation bias is introduced by the readers, it can result in an apparent non-daily deposition rate (e.g., for YFT; see below). This bias

408 can be accounted for in age estimations when reference data is available, such as the data provided by the OTC-tagged tunas. Based on a comparison of micro-increment counts against times-atliberty values (> 300 days) for several fish, our results suggest that the micro-structural features in

411 SKJ otoliths are not suitable for age estimates during their adult phase. In addition, our results show that (i) micro-increment count precision was generally low and strongly variable between readers, (ii) counts tended to underestimate the age of the older, larger BET (> $100 \mathrm{~cm})$, and (iii) the age

414 estimates from otoliths differed widely between readers and teams of readers. The overall variability in otolith reading can strongly affect micro-increment counts and the derived age estimates, and thus, the reader has a major influence on tuna growth estimates that are based solely

417 on otolith data. Therefore, we highly recommend the development of an otolith reference collection made up of known-age or consensus-aged structures. These could then be used to train otolith readers and standardize reading methods between laboratories involved in the aging of tunas. 


\subsection{Estimating SKJ growth}

SKJ have particularly small otoliths that are characterized by irregular micro-incrementation,

423 particularly in old fish. Our analysis of OTC-marked otoliths for SKJ revealed a large discrepancy between micro-increment counts and times-at-liberty, which is similar to the results observed in the Eastern Pacific Ocean (Wild et al., 1995) and Indian Ocean (based on a small dataset of otoliths

426 collected around the Maldives; Adam et al., 1996). In addition, the high variability in microincrement counts observed between and within teams of readers highlights the difficulties associated with interpreting SKJ otoliths. Our data set lacked OTC-marked fish in the $25 \mathrm{~cm}-45$

$429 \mathrm{~cm} F_{L}$ size range, which hindered our assessment of whether a daily deposition rate occurred in the otoliths of immature SKJ (< $40 \mathrm{~cm}$; Stéquert and Ramcharrun 1996, Grande et al. in press). Experiments on laboratory-reared SKJ, over time periods of up to 47 days, indicated that a daily

432 deposition rate occurred in the otoliths of larvae, juveniles, and adult fish (Uchiyama and Struhsaker, 1981; Radtke, 1983; Tanabe et al., 2003a). In addition, Tanabe et al., (2003c) validated the occurrence of a daily deposition rate for small juvenile SKJ $(<4 \mathrm{~cm})$ by analyzing the diel

435 changes in the width of marginal micro-increments Based on the assumption of a daily deposition rate, SKJ otoliths have been used to derive growth curves in the Eastern Indian (Kayama et al., 2004) and Western Pacific Oceans (Leroy, 2000; Tanabe et al., 2003b).

Several hypotheses have been suggested to explain the variability observed in the micro-increment counts of SKJ otoliths. Environmental factors, such as temperature, food availability, and changes

441 in the photoperiod have all been shown to affect the formation of daily growth increments in the otoliths of both temperate and tropical fish (Struhsaker and Uchiyama, 1976; Taubert and Coble, 1977; Wright et al., 1991). SKJ may be exposed to less environmental variation than BET and YFT;

444 although SKJ are able to dive to several hundred meters depth (Schaefer and Fuller, 2007), they 
spend most of their time in tropical surface waters which are characterized by small variations in temperature (Sund et al., 1981; Wild and Hampton, 1994). Furthermore, it might be expected that variations in environmental conditions and prey availability should affect otolith growth for SKJ and the juveniles of BET and YFT in the $30 \mathrm{~cm}-60 \mathrm{~cm} F_{L}$ size range similarly, given that they all form multi-species schools and share similar habitats. Some authors have suggested that SKJ's maturation process and reproductive events may explain the temporal inconsistencies in their otolith growth (Wild and Foreman, 1980; Adam et al., 1996; Leroy, 2000), although evidence to support this hypothesis is limited. SKJ exhibit indeterminate fecundity and spawning in the Indian Ocean 453 takes place year round, with peaks of heightened sexual activity (Stéquert and Ramcharrun, 1996; Grande et al., in press). They continue to feed throughout their spawning period, which is characterized by a continuous recruitment of oocytes which is enabled through a continuous energy 456 supply from the liver that acts as an energy buffer (Grande, 2013). This "income breeding strategy" which allows for SKJ offspring to be provisioned using energy gained concurrently (as distinct from prior accumulation) may bring about changes in feeding intensity that subsequently trigger 459 variations in the energy allocations between growth and reproductive phases and ultimately, could explain the variability observed in micro-incrementation.

462 When direct age reading data are not available, SKJ growth can be derived from mark-recapture experiments by relating observed changes in length between tagging and recovery to the time spent at sea (Maunder, 2002; Gaertner et al., 2008). Such models, however, are required to provide an 465 age-length reference point which anchors the growth curve. For SKJ in the Indian Ocean Eveson et al., (this issue) assumed that the growth curve crosses the origin, i.e., the theoretical age at which fish growth is null and set to 0 . Based on their model, SKJ growth would be very fast during their 468 first year of life, reaching about $20 \mathrm{~cm}, 36 \mathrm{~cm}$, and $45 \mathrm{~cm} F_{L}$ at three, six, and nine months, respectively. In this analysis, the results of Team 2, who analyzed juvenile SKJ otoliths $(20.5 \mathrm{~cm}$ - 
$25 \mathrm{~cm} F_{L} ; n=14$ ) were consistent with the findings of Eveson et al., (this issue), suggesting these

471 fish were aged between three to five months. However, the readings of Team 4 suggested a faster growth for early juveniles. In the Western Central Pacific, SKJ growth derived from otoliths also showed fast growth during the first year with some variability between studies, for example, six-

474 month-old individuals were described as having lengths between $28 \mathrm{~cm}$ and $42 \mathrm{~cm} F_{L}$ (Struhsaker and Uchiyama, 1976; Leroy, 2000; Tanabe et al., 2003b). The collection of otoliths in the $25 \mathrm{~cm}-$ $45 \mathrm{~cm}$ size range is currently in progress to facilitate complementary age-reading analyses which will provide insights into the growth of SKJ juveniles in the Indian Ocean. In the interim, the use of dorsal spines may be a valid alternative for aging adult SKJ. However, this method relies on the assumption that there is an annual deposition of annuli in the spines and this assumption remains untested (Valeiras et al., 2008; Wang et al., 2010).

\subsection{Age estimation of YFT and BET from otoliths}

483 Our results confirm that there is a daily deposition rate in the otoliths of YFT and juvenile BET in the Indian Ocean, as previously observed in captive tunas (Uchiyama and Struhsaker, 1981; Wexler et al., 2001) and wild populations of the Pacific and Atlantic Oceans (Wild and Foreman, 1980;

486 Wild et al., 1995; Hallier et al., 2005; Schaefer and Fuller, 2006). However, deposition rate estimates were found to vary between readers, with one team of readers estimating a mean deposition rate for YFT of $<1 \mathrm{~m} \mathrm{~d}^{-1}$. A daily frequency of micro-increment deposition in otoliths

489 has been observed for many tropical and temperate species and is explained by an endogenous circadian rhythm that controls otolith growth (Pannella, 1971; Campana and Neilson, 1982; Radtke and Dean, 1982; Campana, 1984). External factors, such as temperature or feeding frequency, have

492 been shown to regulate otolith growth, but micro-increment periodicity is only disrupted in extreme cases of physiological stress (Morales-Nin, 2000; see above for the specific case of SKJ). Therefore, we argue that the results for YFT from Team 1 are due to an interpretation bias as 
opposed to other factors.

Within the IOTTP, validating age estimates using OTC-tagged tunas also enabled reader accuracy to 498 be assessed when micro-increment counts for YFT and BET were converted into ages. Age validation is an integral part of the age determination process, whichever method of age estimation (i.e., daily or annual) is selected or aging structure (i.e., otolith, dorsal spine, etc.) is examined 501 (Beamish and McFarlane, 1983; Neilson, 1992). Chemically tagging a percentage of tunas with OTC was a relatively easy, low cost approach to age validation and active consideration should be given to including a similar tagging component in future large-scale mark-recapture experiments.

504 Tagging larger individuals ( $>80 \mathrm{~cm} F_{L}$ ) might enable the recovery of tunas which have spent longer than three years at sea, and hence extend the range of sizes and ages for which age estimates can be validated (Farley et al., 2003). However, the recovery of large YFT and BET may continue to be

507 impaired by the low reporting rates generally seen for longline fisheries (Carruthers et al., this issue).

510 Uncertainties in micro-increment counts (i.e., count precision and interpretation bias) can be exacerbated by poor preparation. Firstly, a non-perpendicular section will require frequent changes in microscope focus and the different reading axes will potentially result in a greater number of

513 count omissions or occurrences of double counting. Secondly, over-grinding the otolith generally results in the removal of some micro-increments, particularly around the nucleus and at the otolith edge. Errors such are these can be incorporated into estimates of age and can eventually propagate

516 into the estimates of somatic growth (Dortel et al., 2013). Finally, over-decalcification can blacken the otolith and make it less readable. Whilst these preparation difficulties can be problematic, it is also possible to take steps to ensure they are reduced as much as possible. However reading 519 uncertainties are mainly due to the natural complexity of tuna otoliths. In particular, several regions 
of the otolith appear to be characterized by sub-daily, or split micro-increments, and overlapping micro-increments. Where these characteristics occur, the subjective opinion and experience of the

522 reader may influence the micro-increment counts. Although low precision was seen in both teams, the less-experienced Team 2 was found to be more precise than the experienced Team 1. Team 2's efforts were solely devoted to reading otoliths whereas Team 1 was also required to work on

525 additional, ongoing research projects. As such, we think that it is likely that this uninterrupted focus allowed Team 2 to develop greater counting precision. We would recommend that future large-scale mark-recapture experiments include a stratified sampling design for otoliths analysis (i.e., species,

528 sex, size-range, area, gear), with different teams identified prior to the project, fully trained, and focused on aging. In this context, reference collections could be used and comparison exercises implemented to define a common reading method, prior to conducting the analysis. These tools

531 could also be used to routinely assess aging errors or inconsistencies in the manner in which age is interpreted (Campana, 2001; Appelberg et al., 2005). Finally, integrated modeling approaches that combine different data sources, including age estimates from different readers, should be

534 preferentially used for determining growth estimates (Dortel et al., submitted; Eveson et al., this issue).

537 The combination of a reduction in micro-increment width due to the allometric relationship between otolith and somatic growth and decreasing growth rates with age may result in some difficulties in identifying micro-increments in the otoliths of large tunas. A scanning electron microscope has been

540 shown to give similar results to a light microscope for YFT and SKJ (Wild et al., 1995; Adam et al., 1996; Stéquert et al., 1996), but its preferential use has been advocated for large BET (> $\left.120 \mathrm{~cm} F_{L}\right)$ because at these sizes, some micro-increments may be too small to be detected otherwise (Stéquert 543 and Conand, 2004). This may partly explain underestimations of age in large BET (Williams et al., 2013), though this did not occur for YFT and micro-increment widths in large YFT and BET are 
very similar ( $1 \mu \mathrm{m})$. Deriving age estimates from counts of annual (as opposed to daily)

546 increment counts may be a more effective strategy for YFT and BET (Farley et al., 2006; Shih et al., 2014). This approach has been validated for BET $>50 \mathrm{~cm} F_{L}$ using 10 otoliths chemically tagged with strontium-chloride with times-at-liberty of longer than 6.5 years (Farley et al., 2003). Counting

549 annual increments is quicker than counting daily micro-increments and appears more precise, though there can be some difficulties in identifying the first annulus and distinguishing between the partially formed increments at the otolith edge (Clear et al., 2000; Farley et al., 2003). The sister

552 otoliths of OTC-tagged tunas that were not prepared for age reading could be used to confirm the applicability of the annual method for both YFT and BET.

\section{Acknowledgments}

The tuna tagging data analyzed in this study were collected through the Indian Ocean Tuna Tagging Program (IOTTP) under the Regional Tuna Tagging Project of the Indian Ocean funded by the $9^{\text {th }}$

558 European Development Fund (9.ACP.RSA.005/006) of the European Union, and small-scale tagging projects funded by the European Union and the Government of Japan, such as the West Sumatra Tuna Tagging Project. We wish to acknowledge the contributions of all the people that

561 have been involved in the IOTTP. This study was funded by the European Union (Reg. 665/2008), the Indian Ocean Tuna Commission (IOTC), ORTHONGEL, the French Ministry of Agriculture and Fisheries, and the Institut de Recherche pour le Développement through grants to FS and ED.

564 We are grateful to Eric Morize, Jean-Marie Munaron, Carys Davies, Claire Geffroy, and Eric Dabas for their contribution to otolith analyses. We particularly thank Jean-Pierre Hallier and Alain Fonteneau for their dedication to the IOTTP and Maud Favier for the organization of the Indian

567 Ocean Tuna Tagging symposium. We are grateful to the Seychelles Fishing Authority for hosting EC, ED, FS, and NB during most of the writing of the manuscript. The SFA sampling teams of Jimy Esparon and Alex Tyrant as well as Rodney Melanie (IOTC) were instrumental in collecting and 
570 sampling the tunas. This work is a contribution of the Agence Nationale de la Recherche EMOTION project (ANR 11 JSV7 007 01). Many thanks to Jane Alpine for editing the manuscript. 
Adam, S., Stéquert, B., Anderson, R.C., 1996. Irregular microincrement deposition on the otoliths of skipjack tuna (Katsuwonus pelamis) from the Maldives, in: Proceedings of the Sixth Expert Consultation on Indian Ocean Tunas. Anganuzzi, A.A. and Webb, N.J., Colombo, pp. 239-244.

Anonymous, 2008. West Sumatra Tuna Tagging Project 2006-2007. Final Report.

Appelberg, M., Formigo, N., Geffen, A.J., Hammer, C., McCurdy, W., Modin, J., Moksness, E., Mosegaard, H., Morales-Nin, B., Troadec, H., Wright, P., 2005. A cooperative effort to exchange age reading experience and protocols between European fish institutes. Fish. Res. 76, 167-173.

Beamish, R.J., McFarlane, G.A., 1983. The forgotten requirement for age validation in fisheries biology. Trans. Am. Fish. Soc. 112, 735-743.

Begg, G.A., Campana, S.E., Fowler, A.J., Suthers, I.M., 2005. Otolith research and application: current directions in innovation and implementation. Marine and freshwater Research 56, 477-483.

Campana, S.E., 1984. Lunar cycles of otolith growth in the juvenile starry flounder Platichthys stellatus. Mar. Biol. 80, 239-246.

Campana, S.E., 1992. Measurement and interpretation of the microstructure of fish otoliths. Can. Spec. Pub. Fish. Aquat. Sci. 59-71.

Campana, S.E., 1999. Chemistry and composition of fish otoliths: pathways, mechanisms and applications. Mar. Ecol. -Progr. Ser. 188, 263-297.

Campana, S.E., 2001. Accuracy, precision and quality control in age determination, including a review of the use and abuse of age validation methods. J. Fish Biol. 59, 197-242.

Campana, S.E., Annand, M.C., McMillan, J.I., 1995. Graphical and statistical methods for determining the consistency of age determinations. Trans. Am. Fish. Soc. 124, 131-138.

Campana, S.E., Neilson, J.D., 1982. Daily growth increments in otoliths of starry flounder (Platichthys stellatus) and the influence of some environmental variables in their production. Can. J. Fish. Aquat. Sci. 39, 937-942.

Campana, S.E., Neilson, J.D., 1985. Microstructure of fish otoliths. Can. J. Fish. Aquat. Sci. 42, 1014-1032.

Campana, S.E., Thorrold, S.R., 2001. Otoliths, increments, and elements: keys to a comprehensive understanding of fish populations? Can. J. Fish. Aquat. Sci. 58, 30-38.

Carruthers, T., Fonteneau, A., Hallier, J.-P., this issue. Estimating tag reporting rates for tropical tuna fleets of the Indian Ocean. Fish. Res.

Chang, W.Y.B., 1982. A statistical method for evaluating the reproducibility of age determination. Can. J. Fish. Aquat. Sci. 39, 1208-1210.

Chen, K.-S., Shimose, T., Tanabe, T., Chen, C.-Y., Hsu, C.-C., 2012. Age and growth of albacore Thunnus alalunga in the North Pacific Ocean. J. Fish Biol. 80, 2328-2344.

Clear, N., Davis, T., Carter, T., 2000. Developing techniques to estimate the age of bigeye tuna and broadbill swordfish off eastern Australia: a pilot project. Final report. CSIRO Marine Research, Hobart.

Dortel, E., Massiot-Granier, F., Rivot, E., Million, J., Hallier, J.-P., Morize, E., Munaron, J.-M., Bousquet, N., Chassot, E., 2013. Accounting for age uncertainty in growth modeling, the case study of yellowfin tuna (Thunnus albacares) of the Indian ocean. PLoS One 8, e60886.

Dortel, E., Sardenne, F., Bousquet, N., Rivot, E., Million, J., Le Croizier, G., Chassot, E., submitted. An integrated Bayesian modeling approach for the growth of yellowfin tuna in the Indian Ocean. Fish. Res.

Driggers, W.B., Grego, J.M., Dean, J.M., 1999. Age and growth of yellowfin tuna (Thunnus albacares) in the western north atlantic ocean. Coll. Vol. Sci. Pap. ICCAT 49, 374-383. 
Eveson, J.P., Laslett, G.M., Polacheck, T., 2004. An integrated model for growth incorporating tag recapture, length frequency, and direct aging data. Canadian Journal of Fisheries and Aquatic Sciences 61, 292-306.

Eveson, J.P., Million, J., Sardenne, F., Le Croizier, G., this issue. Estimating growth of tropical tunas in the Indian Ocean using tag-recapture data and otolith-based age estimates. Fish. Res.

Farley, J., Clear, N., Leroy, B., Davis, T., McPherson, G., 2003. Age and growth of bigeye tuna (Thunnus obesus), from the eastern and western AFZ. CSIRO Marine Research.

Farley, J.H., Clear, N.P., Leroy, B., Davis, T.L., McPherson, G., 2006. Age, growth and preliminary estimates of maturity of bigeye tuna, Thunnus obesus, in the Australian region. Mar. Freshw. Res. 57, 713-724.

Gaertner, D., Delgado de Molina, A., Ariz, J., Pianet, R., Hallier, J.P., 2008. Variability of the growth parameters of the skipjack tuna (Katsuwonus pelamis) among areas in the eastern Atlantic: analysis from tagging data within a meta-analysis approach. Aquat. Living Resour. 21, 349-356.

Grande, M., 2013. The reproductive biology, condition and feeding ecology of the skipjack, Katsuwonus pelamis, in the Western Indian Ocean. Universidad del Pais Vascos, Bilbao, Spain.

Grande, M., Murua, H., Zudaire, I., Goni, N., Bodin, N., in press. Sex ratio, reproductive timing and batch fecundity of the skipjack tuna Katsuwonus pelamis in the western Indian Ocean. J. Fish Biol.

Green, B.S., Mapstone, B.D., Carlos, G., Begg, G.A., 2009. Tropical otoliths - where to next?, Tropical Fish Otoliths: Information for Assessment, Management and Ecology. Springer, Green, Mapstone, Carlos and Begg, Dordrecht.

Griffiths, S.P., Fry, G.C., Manson, F.J., Lou, D.C., 2010. Age and growth of longtail tuna (Thunnus tonggol) in tropical and temperate waters of the central Indo-Pacific. ICES J. Mar. Sci. 67, 125-134.

Hallier, J.-P., 2008. Status of the Indian Ocean Tuna Tagging Programme-RTTP-IO. Presented at the IOTC Working Party on Tagging Data Analysis, Victoria, Seychelles, 30 June-4 July, 2008, IOTC, Victoria, Seychelles, p. 40.

Hallier, J.P., Stéquert, B., Maury, O., Bard, F.X., 2005. Growth of bigeye tuna (Thunnus obesus) in the Eastern Atlantic ocean from tagging-recapture data and otoliths readings. Coll. Vol. Sci. Pap. ICCAT 57, 181-194.

IOTC, 2005. Report of the seventh session of the IOTC Working Party on tropical tunas, Phuket, Thailand, 18-22 July, 2005 ( No. IOTC-2005-WPTT). IOTC, Victoria, Seychelles.

Kayama, S., Tanabe, T., Ogura, M., Okamoto, H., Watanabe, Y., 2004. Daily age of skipjack tuna, Katsuwonus pelamis (Linnaeus), in th eastern Indian Ocean. IOTC Proceedings, WPTT 52.

Lang, K.L., Grimes, C.B., Shaw, R.F., 1994. Variations in the age and growth of yellowfin tuna larvae, Thunnus albacares, collected about the Mississippi River plume. Env. Biol. Fishes 39, 259-270.

Lehodey, P., Hampton, J., Leroy, B., 1999. Preliminary results on age and growth of bigeye tuna (Thunnus obesus) from the Western and Central Pacific Ocean as indicated by daily growth increments and tagging data. Presented at the Twelfth Session of the Standing Committee on Tuna and Billfish, Noumea, New Caledonia, 16-23 June, 1999, SPC, Noumea, New Caledonia, 18p.

Lehodey, P., Leroy, B., 1999. Age and growth of yellowfin tuna (Thunnus albacares) from the western and central Pacific Ocean as indicated by daily growth increments and tagging data. Presented at the Twelfth Session of the Standing Committee on Tuna and Billfish, Noumea, New Caledonia, 16-23 June, 1999, SPC, Noumea, New Caledonia, p. 21.

Leroy, B., 2000. Preliminary results on skipjack (Katsuwonus pelamis) growth. Presented at the 
Thirteenth Session of the Standing Committee on Tuna and Billfish, Noumea, New Caledonia, 5-12 July, 2000, SPC, Noumea, New Caledonia, p. 13.

Lessa, R., Duarte-Neto, P., 2004. Age and growth of yellowfin tuna (Thunnus albacares) in the western equatorial Atlantic, using dorsal fin spines. Fish. Res. 69, 157-170.

Matsumoto, T., 1998. Preliminary analyses of age and growth of bigeye tuna (Thunnus obesus) in the western Pacific Ocean based on otolith increments. Bull. IATTC, Special Report 9, 238242.

Maunder, M.N., 2002. Growth of skipjack tuna (Katsuwomus pelamis) in the eastern Pacific Ocean, as estimated from tagging data. Inter-Am. Trop. Tuna Comm. Bull. 22, 93-131.

Morales-Nin, B., 2000. Review of the growth regulation processes of otolith daily increment formation. Fish. Res. 46, 53-67.

Neilson, J.D., 1992. Sources of error in otolith microstructure examination, in: Otolith Microstructure Examination and Analysis. D.K. Stevenson and S.E. Campana, pp. 115-126.

Panfili, J., De Pontual, H., Troadec, H., Wright, P.J., 2002. Manual of fish sclerochronology. IFREMER-IRD, Brest, France.

Pannella, G., 1971. Fish otoliths: Daily growth layers and periodical patterns. Science 173, 11241127.

Pannella, G., 1974. Otolith growth patterns: an aid in age determination in temperate and tropical fishes, in: The Proceedings of an International Symposium on the Ageing of Fish. Bagenal, T., pp. 28-39.

Prince, E.D., Lee, D.W., Javech, J.C., 1985. Internal zonations in sections of vertebrae from Atlantic Bluefin Tuna, Thunnus thynnus, and their potential use in age determination. Can. J. Fish. Aquat. Sci. 42, 938-946.

Radtke, R.L., 1983. Otolith formation and increment deposition in laboratory-reared skipjack tuna, (Euthynnus pelamis), larvae, in: Proceedings of the International Workshop on Age Determination of Oceanic Pelagic Fishes: Tunas, Billfishes and Sharks, NOAA Technical Report NMFS. Prince E.D. and Pulos L.M., Miami, USA, pp. 99-103.

Radtke, R.L., Dean, J.M., 1982. Increment formation in the otoliths of embryos, larvae, and juveniles of the mummichog, (Fundulus heteoclitus). Fish. Bull. 80, 201-214.

Rodriguez-Marin, E., Olafsdottir, D., Valeiras, J., Ruiz, M., Chosson-Pampoulie, V., RodriguezCabello, C., 2006. Ageing comparison from vertebrae and spines of bluefin tuna (Thunnus thynnus) coming from the same specimen. ICCAT Col. Vol. Sci. Pap. 59, 868-876.

Schaefer, K.M., Fuller, D.W., 2006. Estimates of age and growth of Bigeye Tuna (Thunnus obesus) in the Eastern Pacific Ocean, based on otolith increments and tagging data. Inter-Am. Trop. Tuna Comm. Bull. 23, 35-76.

Schaefer, K.M., Fuller, D.W., 2007. Vertical movement patterns of skipjack tuna (Katsuwonus pelamis) in the eastern equatorial Pacific Ocean, as revealed with archival tags. Fish. Bull. 105, 379-389.

Secor, D.H., Dean, J.M., Campana, S.E., Miller, A.B., Research, B.W.B.I. for M.B. and C., 1995. Recent developments in fish otolith research. Published for the Belle W. Baruch Institute for Marine Biology and Coastal Research by the University of South Carolina Press.

Shih, C.-L., Hsu, C.-C., Chen, C.-Y., 2014. First attempt to age yellowfin tuna, Thunnus albacares, in the Indian Ocean, based on sectioned otoliths. Fisheries Research 149, 19-23.

Shuford, R.L., Dean, J.M., Stéquert, B., Morize, E., 2007. Age and growth of yellowfin tuna in the Atlantic Ocean. Collective Volume of Scientific Papers ICCAT, Coll. Vol. Sci. Pap. ICCAT 60, 330-341.

Spiegelhalter, D., Thomas, A., Best, N., Lunn, D., 2011. OpenBUGS version 3.2.1 user manual.

Stéquert, B., 1995. Détermination de l’âge des thons tropicaux à partir de leurs otolithes : exemple du Yellowfin (Thunnus albacares). Document Technique du Centre ORSTOM de Brest 131. 
Stéquert, B., Conand, F., 2000. Preliminary studies of age and growth of bigeye tuna (Thunnus obesus) in the western indian ocean. IOTC Proceedings 3, $249-255$.

Stéquert, B., Conand, F., 2004. Age and growth of bigeye tuna (Thunnus obesus) in the Western Indian Ocean. Cybium 28, 163-170.

Stéquert, B., Panfili, J., Dean, J.M., 1996. Age and growth of yellowfin tuna (Thunnus albacares), from the Western Indian Ocean, based on otolith microstructure. Fish. Bull. 94, 124-134.

Stéquert, B., Ramcharrun, B., 1996. La reproduction du listao (Katsuwonus pelamis) dans le bassin ouest de l’océan Indien. Aquat. Living Resour. 9, 235-247.

Struhsaker, P., Uchiyama, J.H., 1976. Age and growth of Nehu, Stolephorus purpureus (PiscesEngraulidae), from Hawaiian island as indicated by daily growth increments of sagittae. Fish. Bull. 74, 9-17.

Sun, C.-L., Huang, C.-L., Yeh, S.-Z., 2001. Age and growth of the bigeye tuna, Thunnus obesus, in the western Pacific Ocean. Fish. Bull. 99.

Sund, P.N., Blackburn, M., Williams, F., 1981. Tunas and their environment in the Pacific Ocean: a review. Oceanography and Marine Biology: an Annual Review 19, 443-512.

Tanabe, T., Kayama, S., Ogura, M., 2003a. An outline of the growth study on skipjack tuna (Katsuwonus pelamis) in the western pacific, in: IOTC Proceedings. Presented at the Fifth Session of the IOTC Working Party on Tropical Tunas, Victoria, Seychelles, 3-12 June, 2003, IOTC, Victoria, Seychelles, pp. 156-164.

Tanabe, T., Kayama, S., Ogura, M., 2003b. Precise age determination of young to adult skipjack tuna (Katsuwonus pelamis) with validation of otolith daily increment. Presented at the Sixteenth meeting of the Standing Committee on Tuna and Billfish, SPC, Mooloolaba, Australia, p. 12.

Tanabe, T., Kayama, S., Ogura, M., Tanaka, S., 2003c. Daily increment formation in otoliths of juvenile skipjack tuna Katsuwonus pelamis. Fish. Sci 69, 731-737.

Taubert, B.D., Coble, D.W., 1977. Daily rings in otoliths of three species of Lepomis and Tilapia mossambica. J. Fish. Res. Board. Can. 34, 332-340.

Uchiyama, J.H., Struhsaker, P., 1981. Age and growth of skipjack tuna, Katsuwonus pelamis, and yellowfin tuna, Thunnus albacares, as indicated by daily growth increments of sagittae. Fish. Bull. 79, 151-162.

Valeiras, X., Macias, D., Gomez, M.J., Lema, L., Godoy, D., Ortiz de Urbina, J.M., de la Serna, J.M., 2008. Age and growth of Atlantic little tuna (Euthynnus alleteratus) in the western Mediterranean Sea, in: Tropical Tunas $=$ Thonidés Tropicaux $=$ Tunidos Tropicales, ICCAT Col. Vol. Sci. Pap. ICCAT, Madrid, Spain, pp. 1638-1648.

Viera, A., 2005. Study of the growth of yellowfin tuna (Thunnus albacares) in the Indian Ocean based on the length frequency data from 2000 to 2004. Presented at the Seventh Session of the IOTC Working Party on Tropical Tunas, Phuket, Thailand, 18-22 July 2005, IOTC, Phuket, Thailand, p. 17.

Von Bertalanffy, L., 1938. A quantitative theory of organic growth (inquiries on growth laws. II). JSTOR: Human Biology 10, 181-213.

Wang, X.-F., Xu, L.-X., Zhu, G.-P., Wang, C.-L., 2010. Age identification and growth characteristics of Katsuwonus pelamis in western and central Pacific Ocean. Ying Yong Sheng Tai Xue Bao 21, 756-762.

Wexler, J.B., Chow, S., Wakabayashi, T., Nohara, K., Margulies, D., 2007. Temporal variation in growth of yellowfin tuna (Thunnus albacares) larvae in the Panama Bight, 1990. Fish. Bull. 105, 1-18.

Wexler, J.B., Margulies, D., Masuma, S., Tezuka, N., Teruya, K., Oka, M., Kanematsu, M., Nikaido, H., 2001. Age validation and growth of yellowfin tuna, Thunnus albacares, larvae reared in the laboratory. Inter-Am. Trop. Tuna Comm. Bull. 22, 52-71.

Wild, A., Foreman, T.J., 1980. The relationship between otolith increments and time for yellowfin 
and skipjack tuna marked with tetracycline. Inter-Am. Trop. Tuna Comm. Bull. 17, 507560.

Wild, A., Hampton, J., 1994. A review of the biology and fisheries for skipjack tuna, Katsuwonus pelamis, in the Pacific Ocean. FAO Fisheries Technical Paper.

Wild, A., Wexler, J.B., Foreman, T.J., 1995. Extended studies of increment deposition rates in otoliths of yellowfin and skipjack tunas. Bull. Mar. Sci. 57, 555-562.

Williams, A.J., Leroy, B., Nicol, S.J., Farley, J.H., Clear, N.P., Krusic-Golub, K., Davies, C.R., 2013. Comparison of daily- and annual- increment counts in otoliths of bigeye (Thunnus obesus), yellowfin (T. albacares), southern bluefin (T. maccoyii) and albacore (T. alalunga) tuna. ICES J. Mar. Sci. 70, 1439-1450.

Wright, P.J., Rowe, D., Thorpe, J.E., 1991. Daily growth increments in the otoliths of Atlantic salmon parr, Salmo salar L., and the influence of environmental factors on their periodicity. J. Fish Biol. 39, 103-113.

Yamanaka, K.L., 1990. Age, growth and spawning of yellowfin tuna in the southern Philippines, Publications of the Indo-Pacific Tuna Development and Management Programme. IPTP, Colombo, Sri Lanka. 


\section{Table captions}

Table 1. Summary of studies that have used otolith micro-structures to estimate the age and growth of tropical tunas in the Eastern Pacific Ocean (EPO), Western Central Pacific Ocean (WCPO), Atlantic Ocean (AO), and Indian Ocean (IO) outlining the otolith section that was read (Whole otolith (WO); External surface (ES); Frontal section (FS); Transverse section (TS)) and which experiment type was used to source the otoliths (mark-recapture experiments using oxytetracycline (MR) or captive experiments (CE)), where the number of tunas considered (N) are given for yellowfin (YFT), skipjack (SKJ), and bigeye (BET).

Table 2. The four teams of otolith readers and the reading equipment according to measurement method, used in this analysis. From left to right, the columns detail each team of readers's: institute of affiliation, prior experience reading tuna otoliths, assistance received from experienced readers, the number of readers in the team, the number of otoliths read for each species (i.e., bigeye (BET); skipjack (SKJ); and yellowfin tuna (YFT)), and the reading equipment (optical microscope $(\mathrm{OM})$ linked to a computer screen and binocular $(\mathrm{B}))$ used to measure the length of the otolith section $\left(L_{O}\right)$, the number of micro-increments from the oxytetracycline mark to the otolith edge $\left(I_{m}\right)$, and the number of micro-increments from the nucleus to the otolith edge $\left(I_{t}\right)$.

Table 3. A summary of the linear models used to investigate the relationship between micro-increment counts from the oxytetracycline mark to the otolith edge $\left(I_{m}\right)$ and times-at-liberty $(D)$ by team of readers (mean, standard deviation (SD), and the $2.5 \%$ and $97.5 \%$ quantiles of the posterior distributions of the regression parameters). 
Table 4. Number of otoliths read $(\mathrm{N})$ and the coefficient of variation $(\mathrm{CV}$; \%) of the micro-increment counts by reading team for each of the three tuna species. 
Table 1.

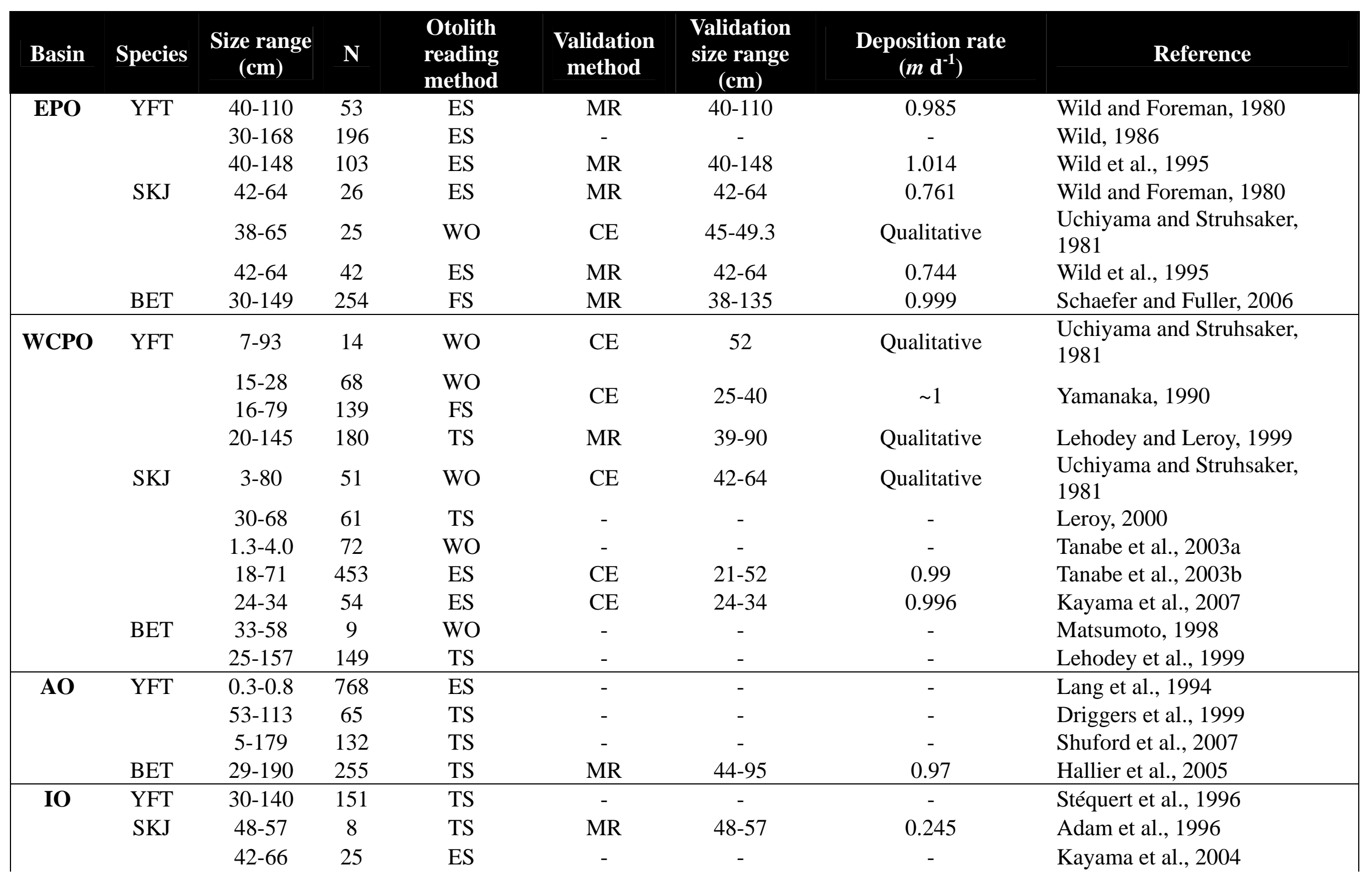


Table 2.

ID \begin{tabular}{l|l|l|c|c|} 
Institute & Experience & Assistance & $\begin{array}{c}\text { Number of } \\
\text { readers }\end{array}$ & $\begin{array}{c}\text { Species } \\
\text { BET } \mid \text { SKJ }|| \text { YFT }\end{array} \mid$ Lo measure $\mid I_{m}$ and $I_{t}$ counts
\end{tabular}

\begin{tabular}{|c|c|c|c|c|c|c|c|c|c|}
\hline 1 & IRD & $>2 \mathrm{y}$ & Yes & 3 & 89 & 18 & 197 & OM & OM \\
\hline 2 & IRD & $<2 \mathrm{y}$ & No & 2 & 61 & 39 & 119 & OM / B & OM \\
\hline 3 & IRD & $<2 \mathrm{y}$ & Yes & 1 & 137 & - & - & OM & OM \\
\hline 4 & SPC & $>2 \mathrm{y}$ & No & 1 & - & 29 & - & - & OM \\
\hline
\end{tabular}


Table 3.

\begin{tabular}{|c|c|c|c|c|c|c|c|c|}
\hline \multirow[t]{2}{*}{ Species } & \multirow{2}{*}{$\begin{array}{c}\text { Reader } \\
\text { team }\end{array}$} & \multirow[t]{2}{*}{$\mathrm{N}$} & \multirow{2}{*}{$\begin{array}{l}\text { Size range } \\
(\mathrm{cm})\end{array}$} & \multirow[t]{2}{*}{ Parameter } & \multirow[t]{2}{*}{ Mean } & \multirow[t]{2}{*}{ SD } & \multicolumn{2}{|c|}{$\begin{array}{l}\text { Posterior } \\
\text { quantiles }\end{array}$} \\
\hline & & & & & & & $2.5 \%$ & $97.5 \%$ \\
\hline \multirow[t]{6}{*}{ Bigeye } & 1 & 65 & $46-117.3$ & $a$ & 0.99 & 0.02 & 0.94 & 1.03 \\
\hline & & & & $b$ & -0.14 & 0.82 & -1.63 & 1.58 \\
\hline & 2 & 29 & 49.5-141.6 & $a$ & 0.99 & 0.03 & 0.93 & 1.05 \\
\hline & & & & $b$ & 7.39 & 2.51 & 3.21 & 12.29 \\
\hline & 3 & 115 & $46-141.6$ & $a$ & 0.96 & 0.02 & 0.92 & 0.99 \\
\hline & & & & $b$ & -0.50 & 0.38 & -1.17 & 0.21 \\
\hline \multirow[t]{6}{*}{ Skipjack } & 1 & 9 & $48.5-56.9$ & $a$ & 0.51 & 0.08 & 0.34 & 0.66 \\
\hline & & & & $b$ & 6.00 & 7.21 & -7.65 & 20.47 \\
\hline & 2 & 25 & $48.6-60.2$ & $a$ & 0.16 & 0.02 & 0.13 & 0.20 \\
\hline & & & & $b$ & 10.89 & 2.83 & 0.86 & 15.32 \\
\hline & 4 & 15 & $48.6-60.2$ & $a$ & 0.17 & 0.03 & 0.13 & 0.23 \\
\hline & & & & $b$ & 7.39 & 4.36 & -0.92 & 15.64 \\
\hline \multirow[t]{4}{*}{ Yellowfin } & 1 & 90 & $49.8-135.4$ & $a$ & 0.88 & 0.02 & 0.84 & 0.92 \\
\hline & & & & $b$ & -0.14 & 0.82 & -1.63 & 1.58 \\
\hline & 2 & 39 & 47.9-135.4 & $a$ & 0.98 & 0.03 & 0.92 & 1.04 \\
\hline & & & & $b$ & 7.39 & 2.51 & 3.21 & 12.29 \\
\hline
\end{tabular}


Table 4.

\begin{tabular}{|c|c|c|c|c|c|c|c|}
\hline Species & & m 1 & & m 2 & & am 3 & Team 4 \\
\hline & $\mathrm{N}$ & CV & $\mathrm{N}$ & $\mathrm{CV}$ & N & $\mathrm{CV}$ & $\mathrm{N} C \mathrm{CV}$ \\
\hline Bigeye & 89 & 62.9 & 61 & 21.2 & 137 & 67.8 & \\
\hline Skipjack & 18 & 70 & 39 & 9.7 & & & 295.5 \\
\hline Yellowfin & 197 & 32.8 & 119 & 23.8 & & & \\
\hline Total & 304 & 41.3 & 219 & 20.2 & 137 & 67.8 & 295.5 \\
\hline
\end{tabular}




\section{Figure captions}

Figure 1. The location of 415 tunas (137 bigeye, 57 skipjack, and 221 yellowfin) for which

576 geographic coordinates were available. In cases where uncertainty around the location existed, the mean latitudes and longitudes of the relevant fishing sets were calculated to provide an approximate location.

Figure 2. Image of a yellowfin tuna otolith showing (a) the full transverse section with linear measurement segments $L_{1}$ and $L_{2}$ (used to compute $L_{O}$; black arrows); (b) an otolith section showing 582 the counting path (maximal growth axis) with detected micro-increments (white ticks); (c) an otolith section showing two zones where subjective interpretation is required, the black oval identifying where micro-increments had to be interpolated and the black rectangle identifying where

585 there is some overlap in the micro-increments; and (d) an otolith section (black zone represents the otolith edge) illustrating differences in image resolution (left versus right sides of the dashed line) when the microscope is focused on the reading section. White arrows indicate the reading axis (b588 d).

Figure 3. The relationship between otolith growth and somatic growth for (a) bigeye (BET; $n=$ 591 140), (b) skipjack (SKJ; $n=63$ ), and (c) yellowfin (YFT; $n=223$ ), where $L_{O}$ is the length of otolith section $(\mu \mathrm{m})$ measured along the maximal growth axis, and $F_{L}$ is the fork length $(\mathrm{cm})$. The solid line indicates the power regression model fitted to the data.

594

Figure 4. The relationship between the micro-increment counts made from the OTC mark to the otolith edge $\left(I_{m}\right)$ and time-at-liberty ( $D$; in days) for (a) bigeye (BET; $n=116$ ), (b) skipjack (SKJ; $597 n=34$ ), and (c) yellowfin (YFT; $n=112$ ). Small vertical lines around the individual symbols indicate the standard deviation for $I_{m}$ and the solid lines indicate the linear regression models fitted 
to the data for each team of readers, with a $95 \%$ confidence interval.

600

Figure 5. A comparison between the micro-increment counts made by the different reading teams for (a-c) bigeye (BET), (d) skipjack (SKJ), and (e) yellowfin (YFT). The horizontal and vertical 603 lines around the individual symbols represent the standard deviation around mean micro-increment counts. The thick solid lines represent the identity lines, and the dashed lines indicate the linear regression model fitted to the data. SKJ otoliths were only read once by Team 4.

606

Figure 6. Growth estimates for (a) bigeye (BET) and (b) yellowfin (YFT) based on the age estimates derived from micro-increment counts made by reading teams 1-3 for 129 BET and 215 609 YFT. 


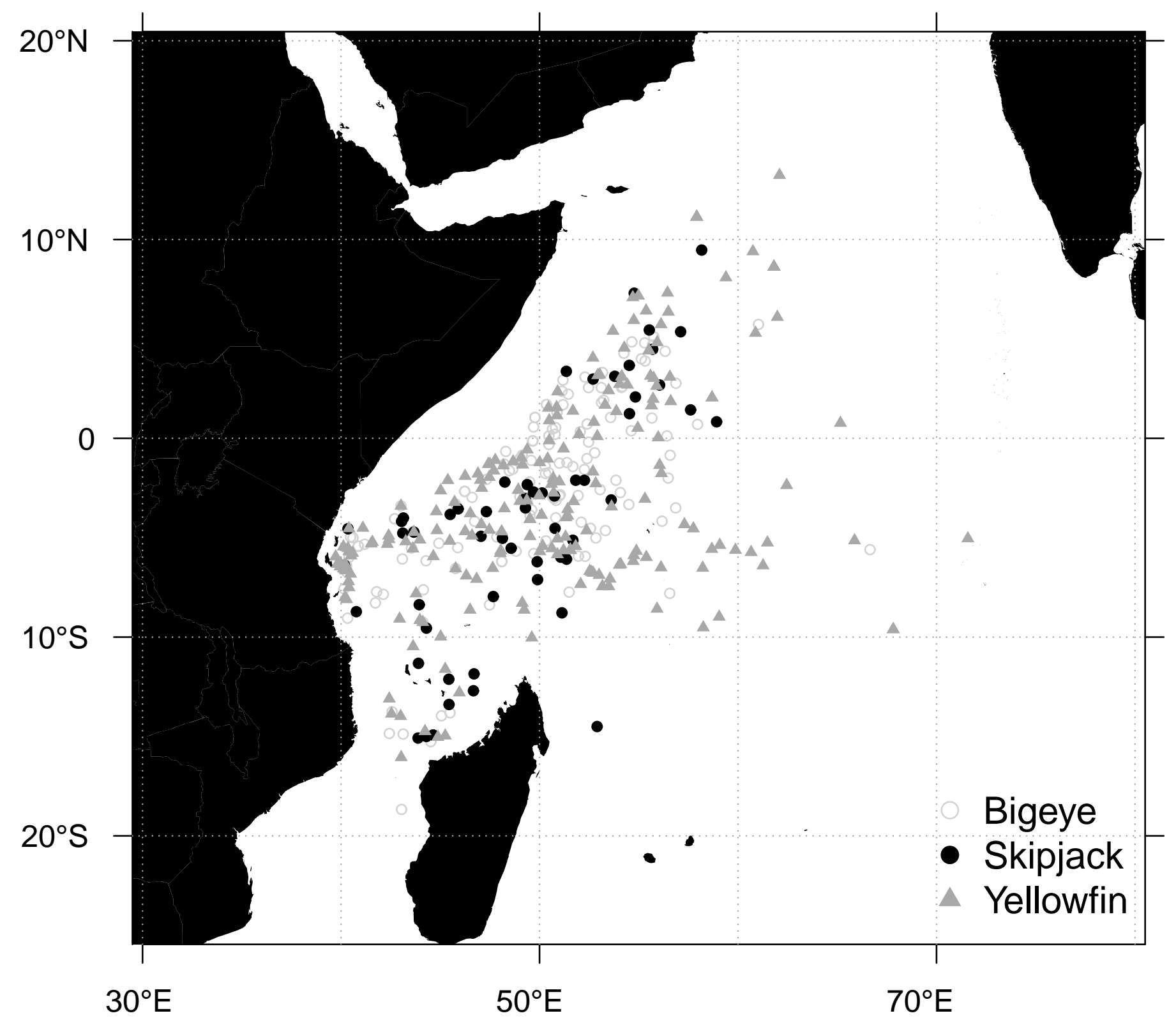



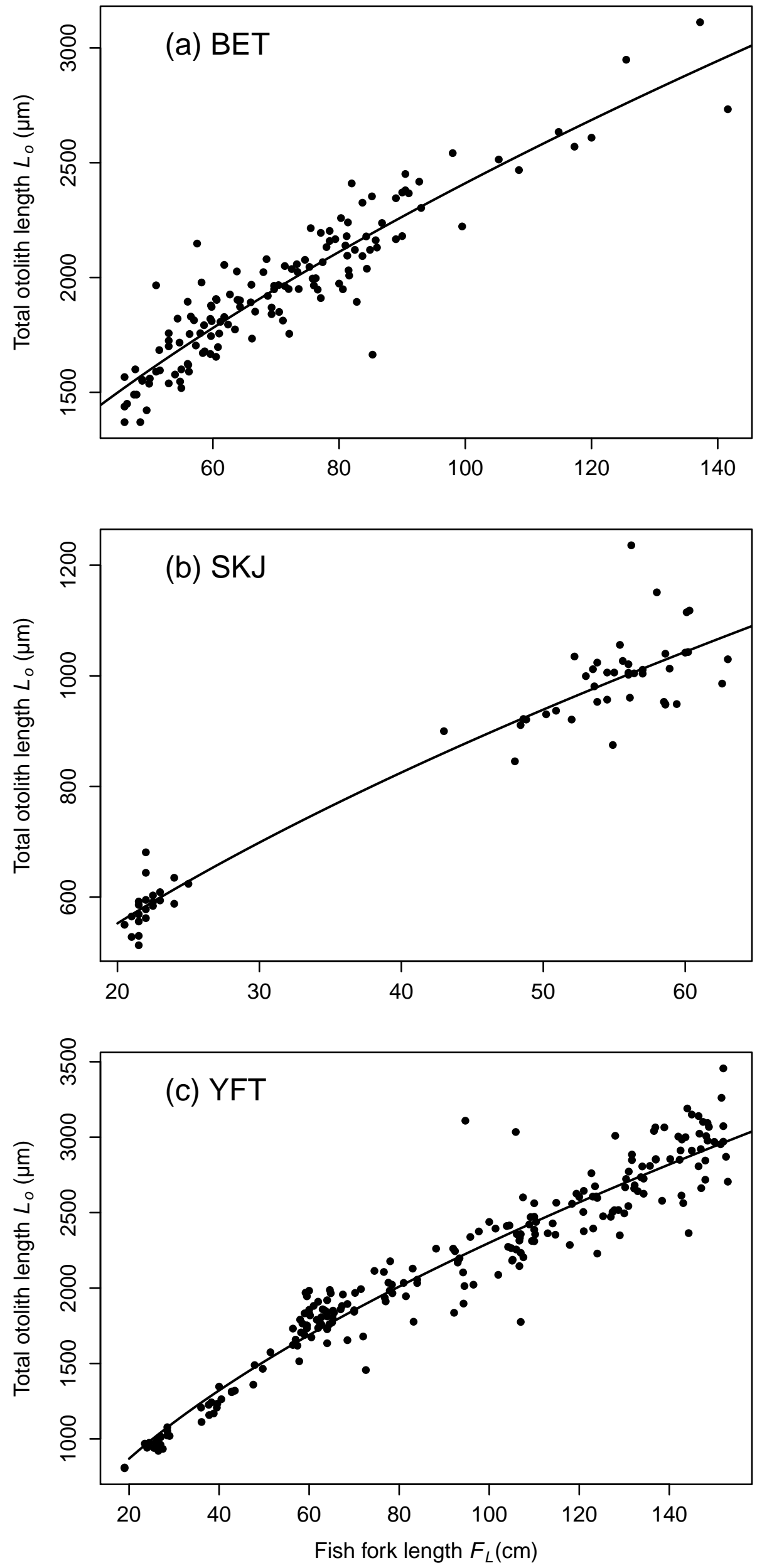

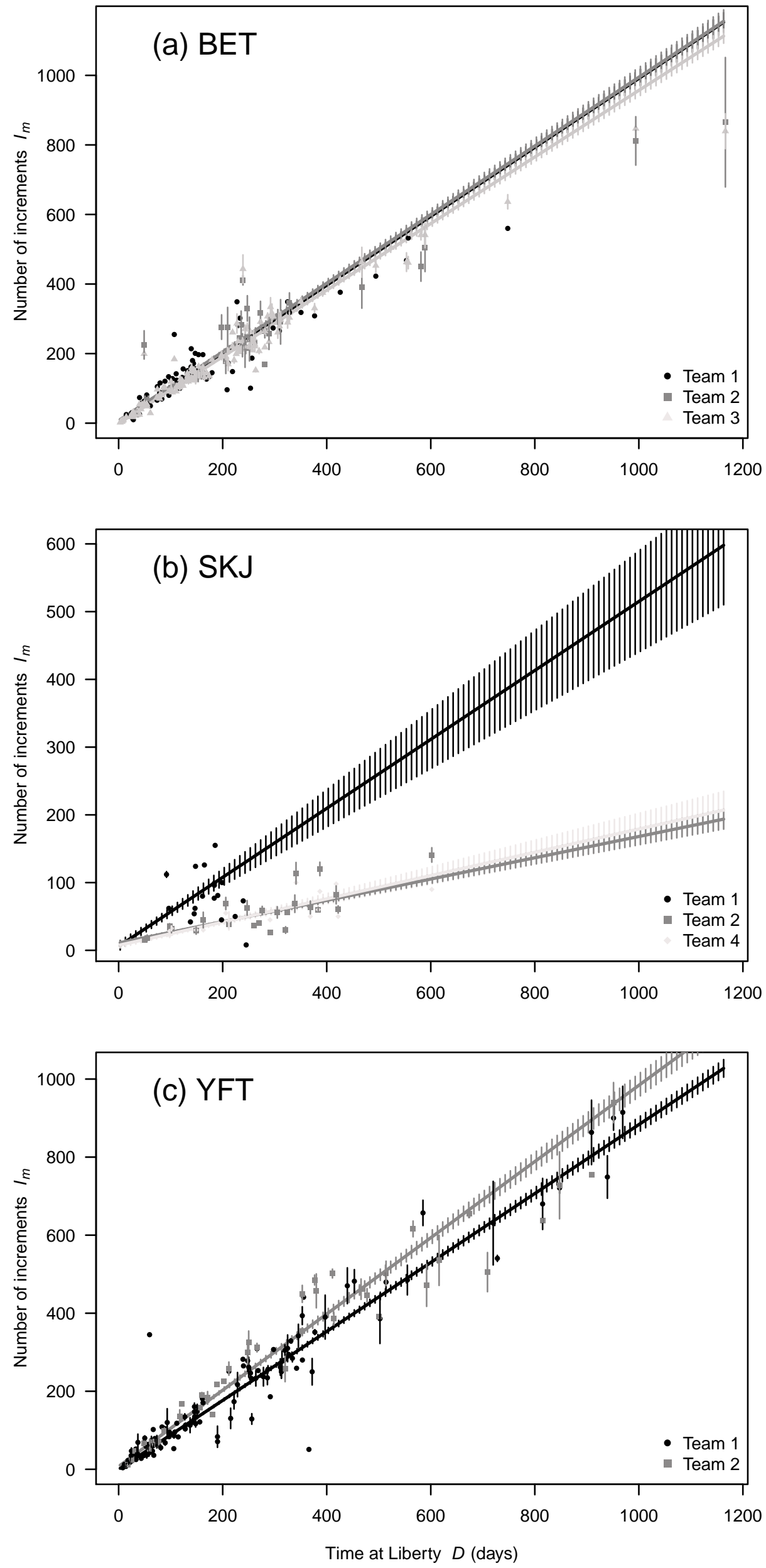

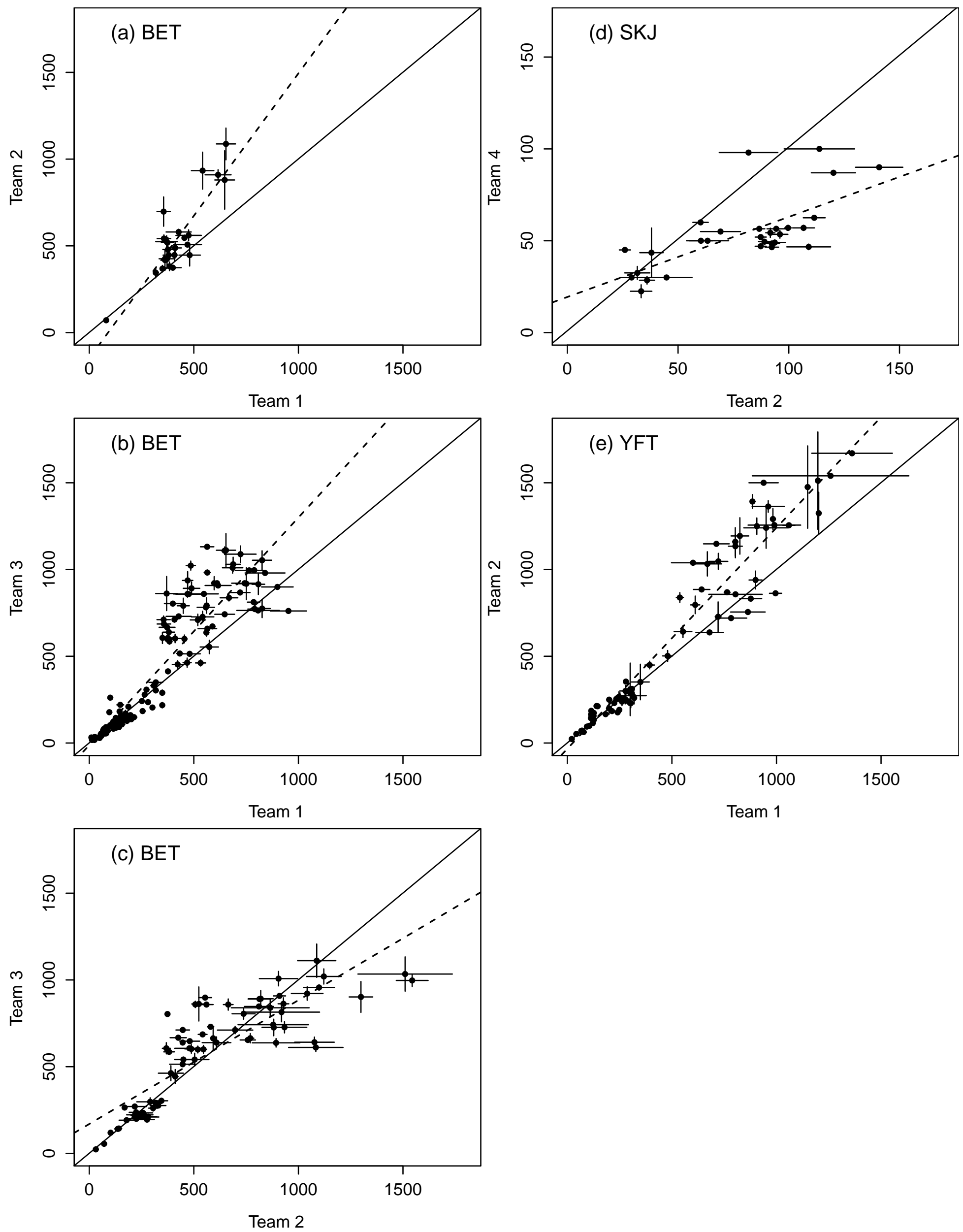


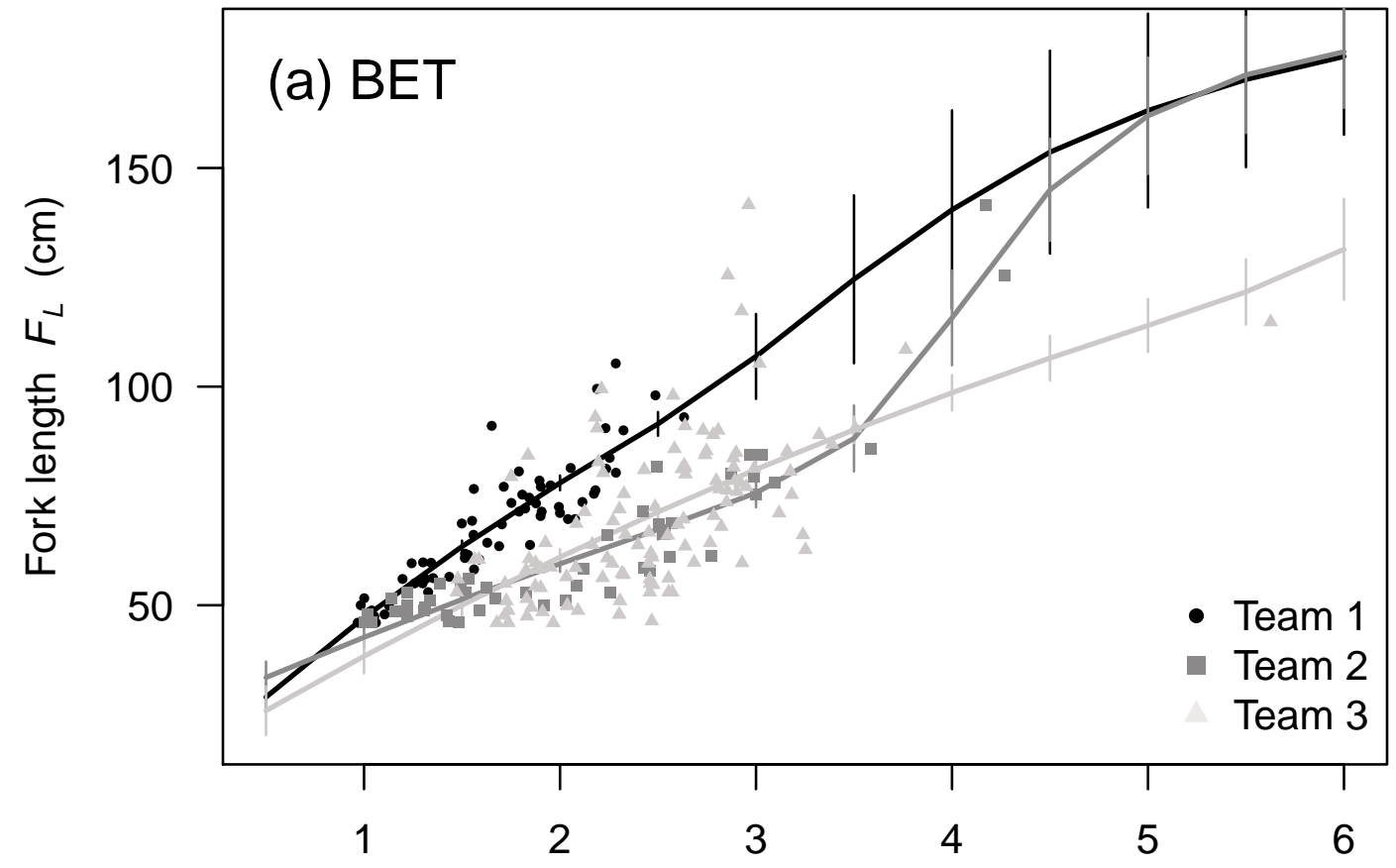

Age estimated (years)

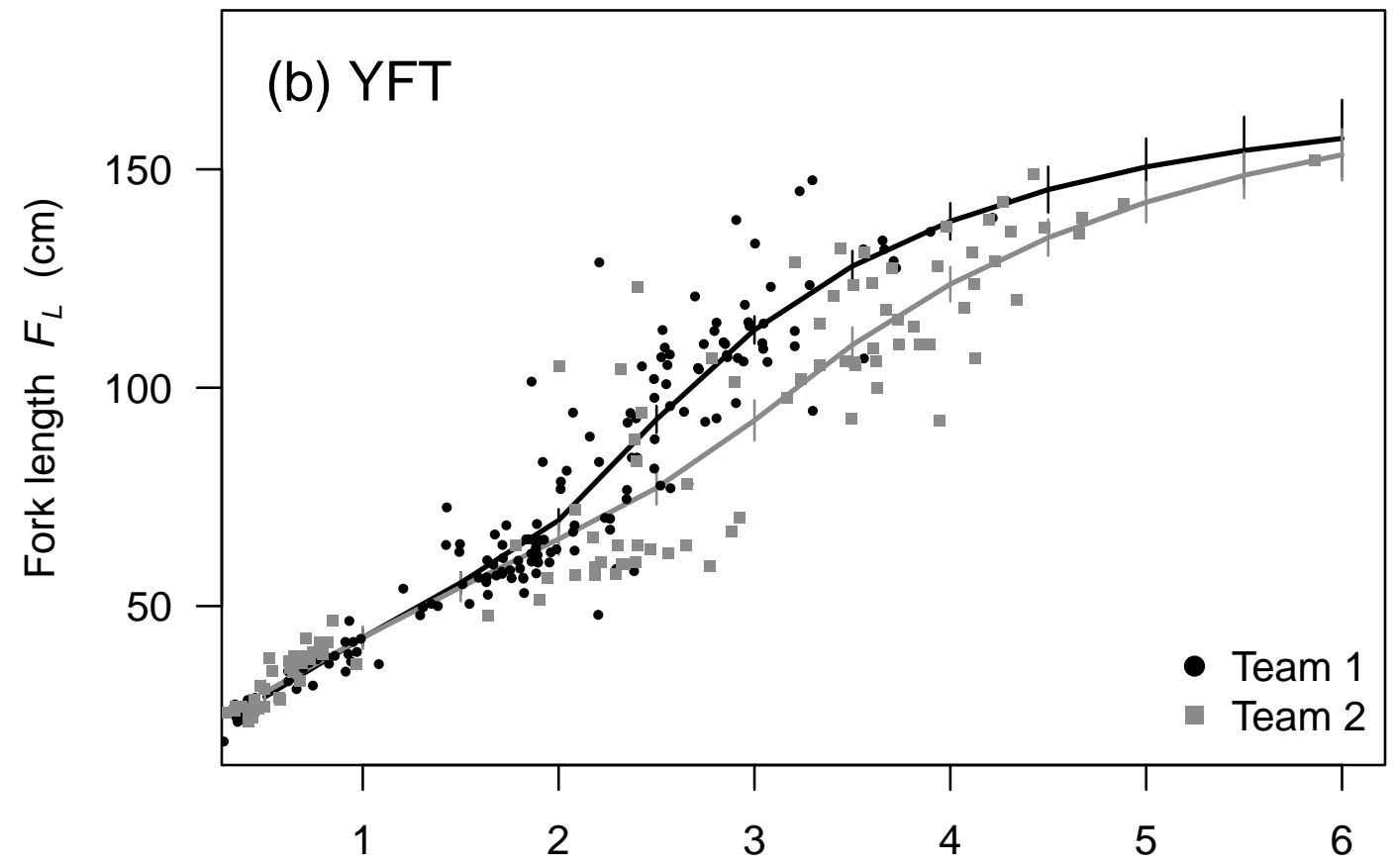

Age estimated (years) 


\section{Supplementary Online Materials}

Methods, results, and caveats

615 Fany Sardenne ${ }^{1,2}$, Emmanuelle Dortel ${ }^{3}$, Gaël Le Croizier ${ }^{1,2}$, Julien Million², Maylis Labonne ${ }^{4}$, Bruno Leroy $^{5}$, Nathalie Bodin ${ }^{1}$, Emmanuel Chassot ${ }^{1}$

$618{ }^{1}$ Institut de Recherche pour le Développement, UMR 212 EME (IRD/Ifremer/UM2), SFA, Fishing Port, BP 570, Victoria, SEYCHELLES

${ }^{2}$ Indian Ocean Tuna Commission, PO Box 1011, Victoria, SEYCHELLES

$621{ }^{3}$ Institut de Recherche pour le Développement, UMR 212 EME (IRD/Ifremer/UM2), Avenue Jean Monnet, BP 171, 34203 Sète Cedex, FRANCE

${ }^{4}$ Institut de Recherche pour le Développement, UMR 6539 LEMAR (UBO/CNRS/IRD/Ifremer), BP

624 70, 29280 Plouzané, FRANCE

${ }^{5}$ Secretariat of the Pacific Community, BP D5, 98848 Nouméa, NEW CALEDONIA

$627{ }^{*}$ Corresponding author. Email: Emmanuel.Chassot@ird.fr; Tel: +248 4670 307; Fax: +248 4224742 


\section{Supplementary figure captions}

Figure S1. Size-frequency histograms of the tunas collected in the Indian Ocean between 2005 and 6332012 by species (a) bigeye (BET; $n=142$ ), (b) skipjack (SKJ; $n=81$ ), and (c) yellowfin (YFT; $n=$ 283), and by tag origin (West Sumatra Tuna Tagging Project (WSTTP) or Regional Tuna Tagging Program (RTTP)) or recoverer (Indian Ocean Tuna Ltd. Cannery; IOT).

636

Figure S2. A comparison between the length measurements of otolith sections $\left(L_{O} ; \mu \mathrm{m}\right)$ taken using the microscope and the binocular for a subset of 155 otoliths. Solid line indicates the regression

639 model and dashed lines indicate the 95\% confidence interval. The linear regression model fitted to the data indicates that there is a strong linear relationship between both reading methods (slope $=$ 1.004; $p<0.001$; Pearson's $r=0.985$ ).

642

Figure S3. A comparison between the length measurements of otolith sections $\left(L_{\circ} ; \mu \mathrm{m}\right)$ made using the binocular by two different readers (A and B) for a subset of 38 otoliths. The correlation between

645 the two sets of $L_{O}$ measurements was found to be highly significant (slope $=0.98 ; p<0.001$; Pearson's $r=0.99)$.

648 Figure S4. The relationship between the mean and standard deviation of micro-increment counts for all tuna otoliths which were read a minimum of five times. The solid line indicates the linear regression model, $I_{m}$ are the micro-increment counts made from the oxytetracycline (OTC) mark to the otolith edge, and $I_{t}$ are the micro-increment counts made from the nucleus to the otolith edge. 


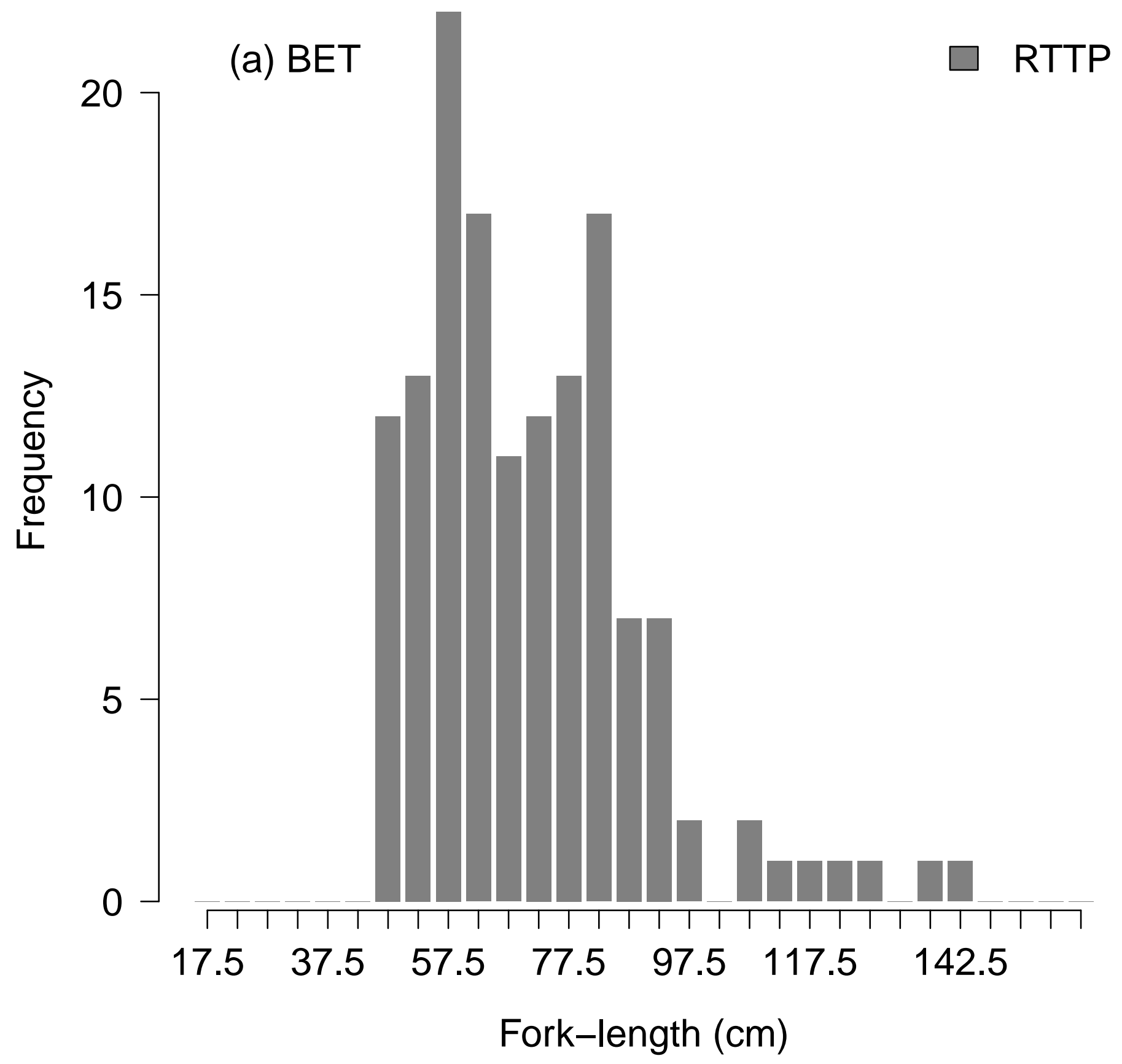




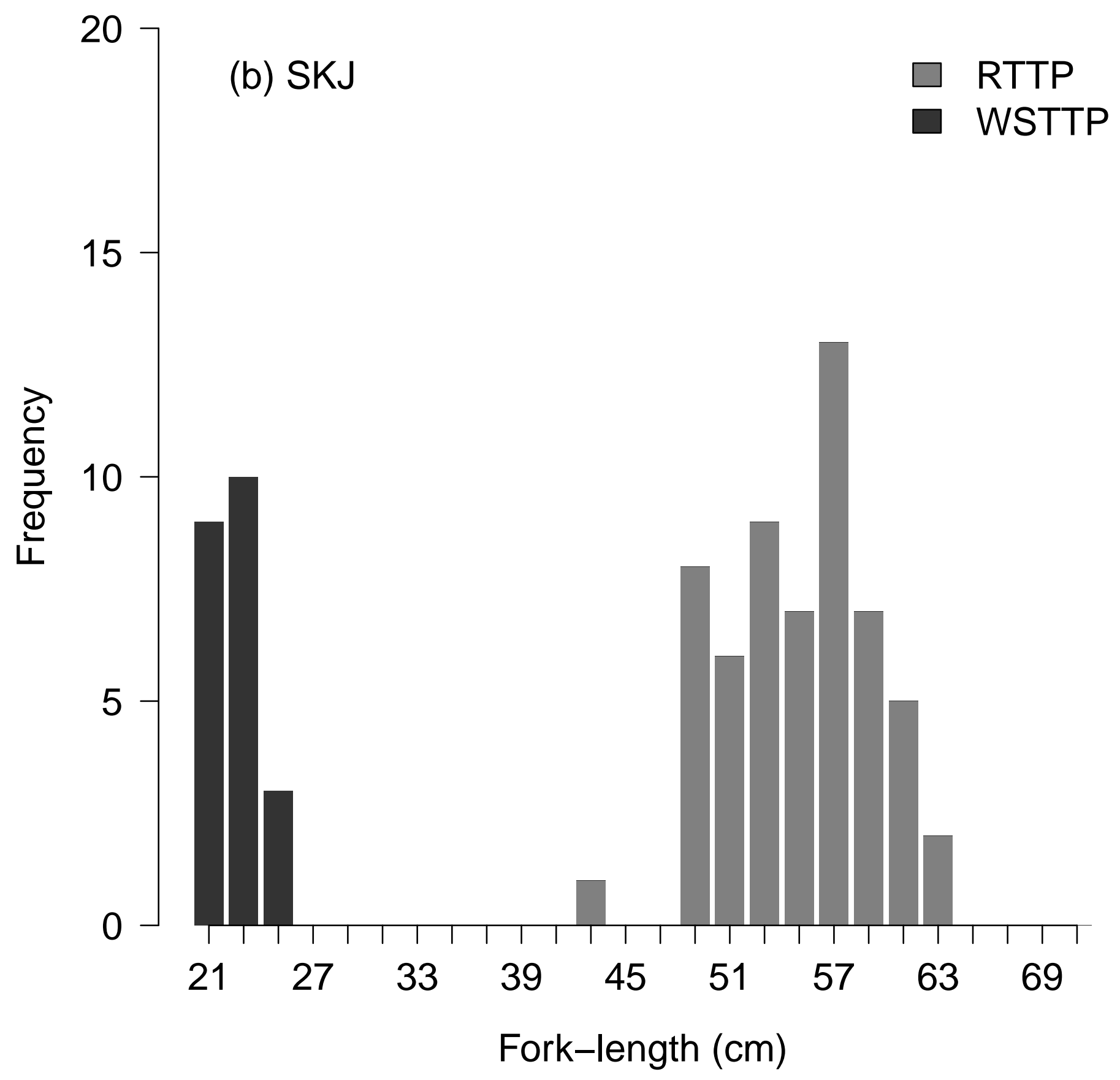




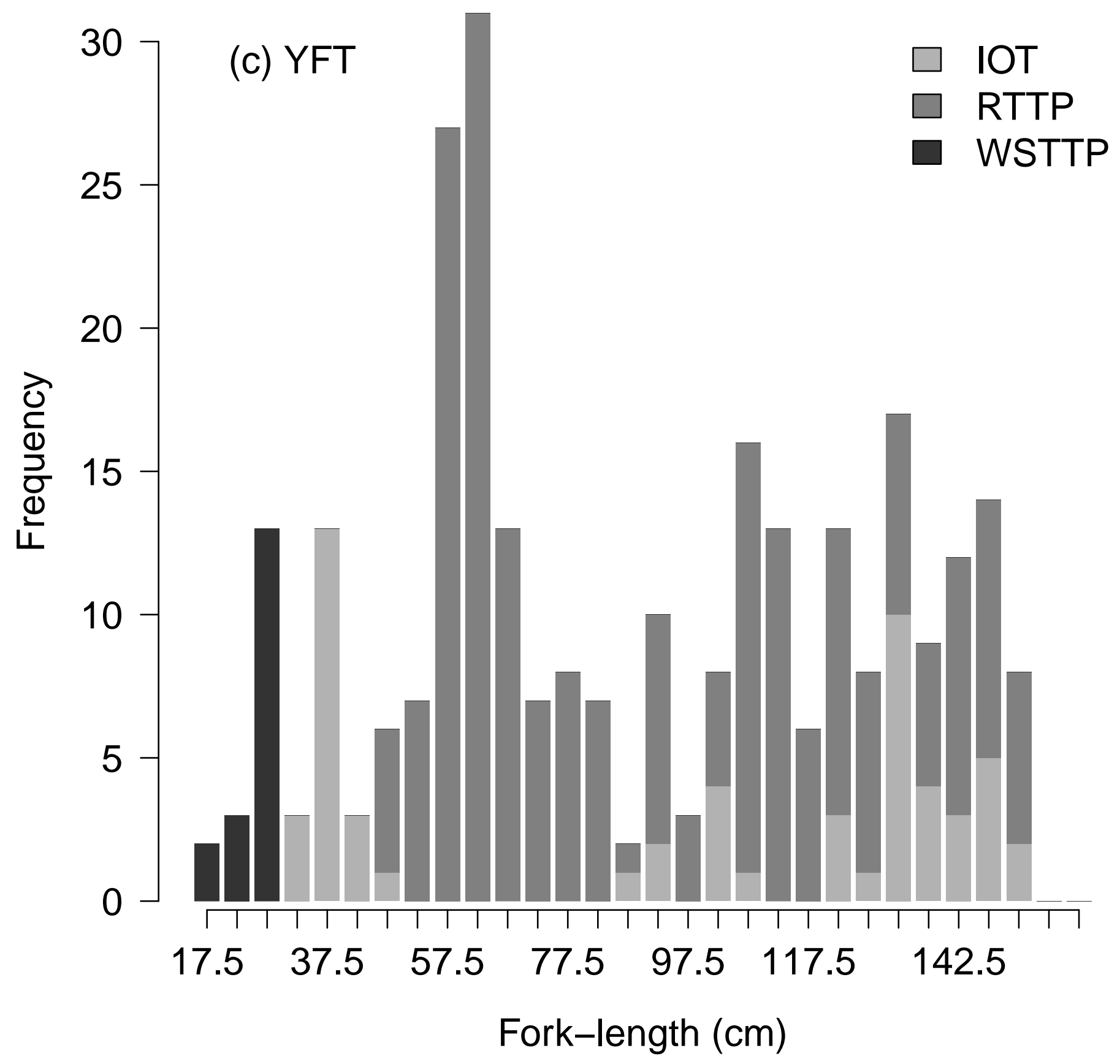




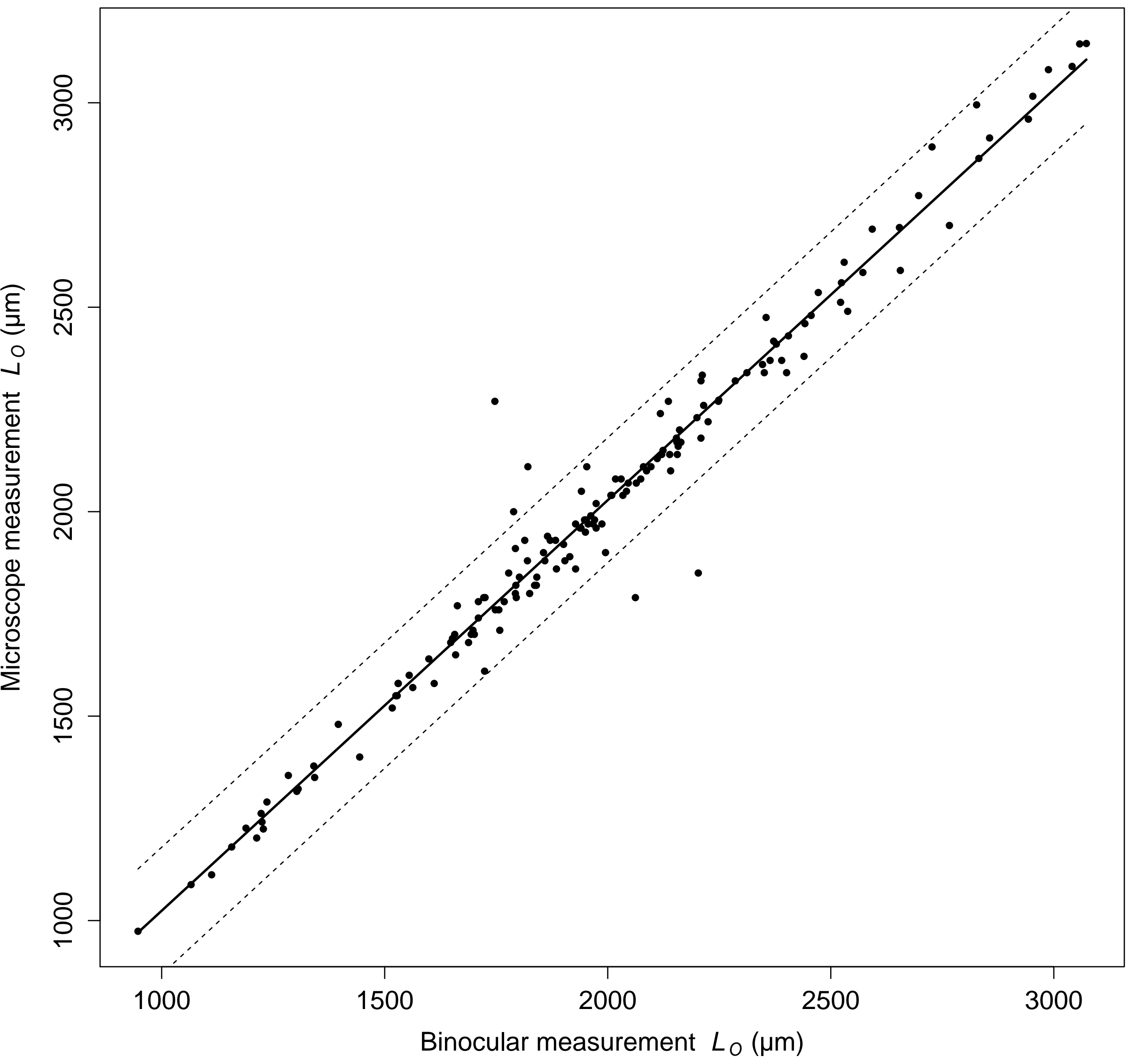




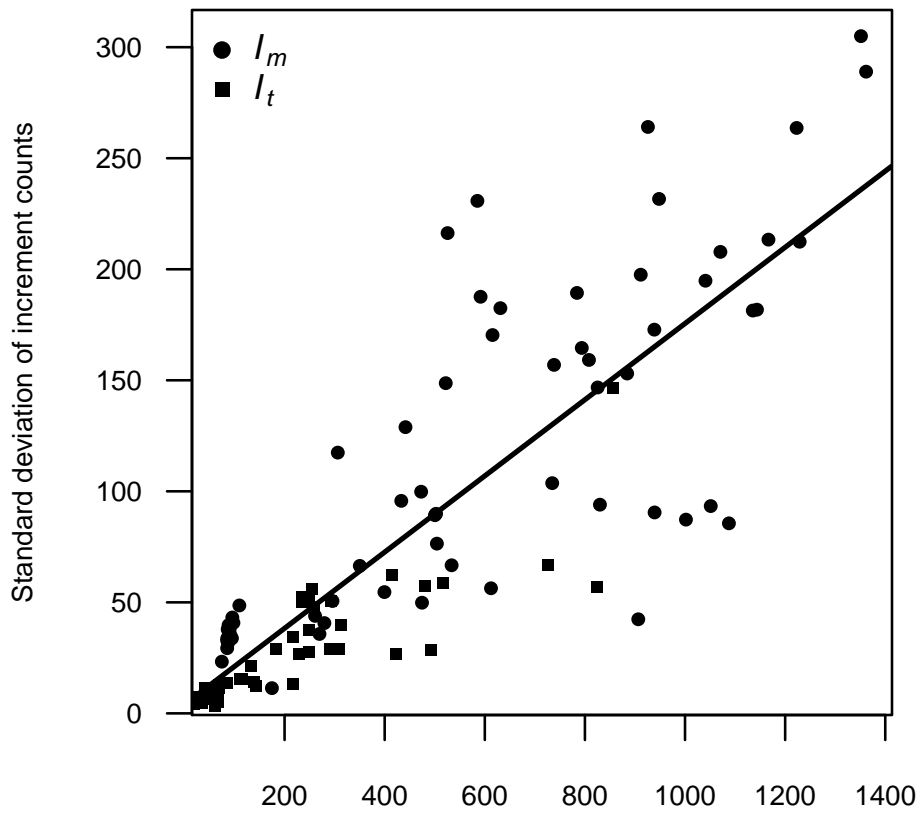

Mean number of increment counts 


\section{Supplementary table captions}

Table S1. The number and size ranges (in brackets; $\mathrm{cm}$ ) of tunas tagged by conventional dart tags (DART) and oxytetracycline (OTC) tags and recovered through the Indian Ocean Regional Tuna

657 Tagging Project, and the associated percent recovery rate (RR). Figures only represent tuna species (bigeye; BET, skipjack; SKJ, and yellowfin; YFT) for whom there was reliable data for species identifications and length measurements at tagging and recapture.

660

Table S2. Prior probability density functions used for the parameters of the regression model. U and $\mathrm{N}$ indicate Uniform and Normal distributions.

663

Table S3. Parameters and variables used in the somatic growth models.

Table S4. Prior distributions used for parameters of somatic growth models. 666

Table S5. Growth curve parameters according to age estimations of each team. 


\section{Complementary information on tagging-recovery operations}

669 Table S1. The number and size ranges (in brackets; $\mathrm{cm}$ ) of tunas tagged by conventional dart tags (DART) and oxytetracycline (OTC) tags and recovered through the Indian Ocean Regional Tuna Tagging Project, and the associated percent recovery rate (RR). Figures only represent tuna species

672 (bigeye; BET, skipjack; SKJ, and yellowfin; YFT) for whom there was reliable data for species identifications and length measurements at tagging and recapture.

\begin{tabular}{|l|r|c|r|r|r|r|}
\hline & \multicolumn{2}{|c|}{ Tagged } & \multicolumn{2}{c|}{ Recovered } & \multicolumn{2}{c|}{ RR (\%) } \\
\hline Species & \multicolumn{1}{|c|}{ DART } & OTC & \multicolumn{1}{c|}{ DART } & OTC & DART & OTC \\
\hline BET & $31630(32-102)$ & $2407(35-96)$ & $4426(37-189)$ & $165(46-150)$ & 14 & 6.86 \\
\hline SKJ & $75993(32-77)$ & $1482(38-67)$ & $10268(39-153)$ & $156(40-69)$ & 13.51 & 10.53 \\
\hline YFT & $51841(32-144)$ & $1993(34-141)$ & $7899(35-168)$ & $215(44-135)$ & 15.24 & 10.79 \\
\hline Total & $159464(32-144)$ & $5882(34-141)$ & $22593(35-189)$ & $536(40-150)$ & 14.17 & 9.11 \\
\hline
\end{tabular}

675 2. Regression model between the time-at-liberty $D$, and the micro-increment count between the OTC mark and otolith edge $I_{m}$

\subsection{Parameters and processes}

678 In order to estimate the micro-increment deposition rate $a$, for each species, the number of increments made between the OTC mark and otolith edge $I_{m}$, was related to the time-at-liberty $D$, according to the following regression model:

681

$$
I_{m}=a_{r} \cdot D+b_{r}
$$

684 where $r$ represents the team of otolith readers and the intercept $b_{r}$, includes the errors in counting and in interpreting missing increments for team. The prior distributions of these parameters are given in Table S2.

687 
Table S2. The prior probability density functions used for the parameters of the regression models 693 fitted for bigeye (BET), skipjack (SKJ), and yellowfin (YFT) expressed in micro-increments per day $\left(m \mathrm{~d}^{-1}\right)$ where $\mathrm{U}$ indicates a uniform distribution and $\mathrm{N}$ indicates a normal distribution.

\begin{tabular}{|c|c|c|c|}
\hline \multicolumn{1}{|c|}{ Species } & Parameter & Unit & Prior distribution \\
\hline YFT, BET & $a$ & $m \mathrm{~d}^{-1}$ & $\mathrm{U}(-10 ; 10)$ \\
\hline SKJ & $a$ & $m \mathrm{~d}^{-1}$ & $\mathrm{U}(-50 ; 50)$ \\
\hline YFT, BET, SKJ & $b$ & $m$ & $\mathrm{~N}(0,50)$ \\
\hline
\end{tabular}

696

2.2. Statistical inference and convergence diagnostic

Estimates of the parameters were evaluated using three Markov Chain Monte Carlo (MCMC) 699 simulations, using a Gibbs sampler as implemented in OpenBugs version 3.2.1 (Spiegelhalter et al., 2011). The convergence of the MCMC to the stationary posterior distribution was evaluated from the Gelman-Rubin diagnostic, based on the ratio of the inter-chain variance on intra-chain variance

702 (this ratio must approach 1 to represent convergence; Gelman and Rubin, 1992). In this analysis, the Gelman-Rubin diagnostic (as computed from second half of MCMC chains), approached 1 for each parameter, indicating that convergence did occur. The marginal posterior distributions were drawn 705 from 300,000 MCMC samples.

\section{Modeling somatic growth}

708 3.1. Bayesian fit of growth model

For modeling the somatic growth of yellowfin and bigeye, we used the Von Bertalanffy logK model developed by Laslett et al., (2002). Thus, the fork length of a fish $i$, at age $A$, is expressed as:

$711 L_{i}=L_{\infty}\left(1-\exp \left(-k_{2}\left(A_{i}-t_{0}\right)\left(\frac{1+\exp \left(-\beta\left(A_{i}-\alpha-t_{0}\right)\right)}{1+\exp (\beta \alpha)}\right)^{k_{1}-k_{2} / \beta}\right) \times \varepsilon_{i}\right.$

All the parameters used in this equation are defined in Table S3. The corresponding prior distributions are given in Table S4. The prior distributions of $k 1, k 2$, and $\alpha$ are based on information

714 from the literature. No information was available for $\beta$ and $t_{0}$; thus, weakly informative distributions 
were assigned.

717 The data set included little information on the asymptotic length $L_{\infty}$; however, it is a particularly important parameter because it determines the shape of the second part of the growth curve. Thus, supplementary information was provided for this parameter through the use of a generalized extreme value distribution (GEV), using available biological knowledge of each species. This approach allowed for the extrapolation of the behavior of the distribution tails from the greatest values of a sample. This thus estimates the occurrence probability of extreme events (Borchani,

723 2010). This distribution was fit based on size measurement data of fresh fish collected between 1952 and 2011 from the European and Seychelles purse seine fisheries, Maldivian pole and line vessels, and Taiwanese and Japanese longliners.

729 Table S3. Parameters and variables used in the somatic growth models.

\begin{tabular}{|l|l|l|}
\hline Parameter & Unit & Description \\
\hline$L_{i}$ & cm & Fork length of fish $i$ \\
\hline$A_{i}$ & $\mathrm{y}$ & Age of fish $i$ \\
\hline$L_{\infty}$ & $\mathrm{cm}$ & Asymptotic length \\
\hline$k 1$ & $\mathrm{y}^{-1}$ & First stanza growth rate coefficient \\
\hline$k 2$ & $\mathrm{y}^{-1}$ & Second stanza growth rate coefficient \\
\hline$\alpha$ & $\mathrm{y}$ & Relative age of change in growth \\
\hline$\beta$ & $\mathrm{y}^{-1}$ & Transition rate between k1 and $\mathrm{k} 2$ \\
\hline$t_{0}$ & $\mathrm{y}$ & Theoretical age of fork length 0 \\
\hline$\varepsilon_{i}$ & $\mathrm{~cm}$ & Process error for fish $i$ \\
\hline
\end{tabular}

Table S4. Prior distributions used for parameters of somatic growth models.

\begin{tabular}{|c|c|}
\hline Prior for yellowfin model & Prior for bigeye model \\
\hline$L_{\infty} \sim G E V(173.141,11.067,-0.3474)$ & $L_{\infty} \sim G E V(187.622,9.189,-0.3313)$ \\
\hline$k_{1} \sim \Gamma(2.778,0.211)$ & $k_{1} \sim \Gamma(4,0.058)$ \\
\hline \multicolumn{2}{|c|}{$K_{2}=K_{1}+\kappa \quad$ with $\kappa \sim U(0,3)$} \\
\hline \multicolumn{2}{|c|}{$\alpha \sim \Gamma(25,1)$} \\
\hline \multicolumn{2}{|c|}{$\beta \sim U(0,30)$} \\
\hline
\end{tabular}




$$
\begin{aligned}
& t_{0} \sim U(-2,0) \\
& \varepsilon_{i} \sim N\left(0, \sigma^{2}\right){ }_{\text {with }} \sigma^{2} \sim \operatorname{In} \overline{v \Gamma(0.01,0.01)}
\end{aligned}
$$

\subsection{Model diagnostic}

Estimates of growth parameters were evaluated using Bayesian inference with OpenBugs

735 (Spiegelhalter et al., 2011). For each parameter, the value of th Gelman and Rubin (1992) diagnostic was close to 1 , indicating convergence. The marginal posterior distributions of growth parameters were generated from 750,000 samples from three MCMCs. A burn-in period of 5,000 iterations was

738 initially rejected and the chain was thinned to each 1,500 samples to estimate the statistics of the growth parameters. 
744 Table S5. Growth curve parameters according to age estimations of each team.

\begin{tabular}{|c|c|c|c|c|c|c|}
\hline Species & $\begin{array}{c}\text { Reader } \\
\text { team }\end{array}$ & $\mathrm{N}$ & $\begin{array}{l}\text { Size range } \\
(\mathrm{cm})\end{array}$ & Parameter & Mean & SD \\
\hline \multirow[t]{18}{*}{ Bigeye } & 1 & 69 & $46-105.3$ & $\mathrm{~L}_{\infty}$ & 189.92 & 10.21 \\
\hline & & & & k1 & 0.237 & 0.032 \\
\hline & & & & k2 & 1.558 & 0.934 \\
\hline & & & & $t_{0}$ & -0.214 & 0.166 \\
\hline & & & & $\alpha$ & 3.948 & 1.754 \\
\hline & & & & $\beta$ & 15.048 & 15.094 \\
\hline & 2 & 46 & $46-141.6$ & $\mathrm{~L}_{\infty}$ & 186.563 & 11.83 \\
\hline & & & & k1 & 0.124 & 0.022 \\
\hline & & & & k2 & 1.34 & 0.664 \\
\hline & & & & $\mathrm{t}_{0}$ & -1.156 & 0.39 \\
\hline & & & & $\alpha$ & 3.669 & 0.929 \\
\hline & & & & $\beta$ & 6.344 & 13.497 \\
\hline & 3 & 113 & $46-141.6$ & $\mathrm{~L}_{\infty}$ & 188.90 & 9.43 \\
\hline & & & & k1 & 0.154 & 0.032 \\
\hline & & & & k2 & 0.938 & 0.895 \\
\hline & & & & $\mathrm{t}_{0}$ & -0.53 & 0.447 \\
\hline & & & & $\alpha$ & 4.602 & 2.634 \\
\hline & & & & $\beta$ & 22.852 & 15.53 \\
\hline \multirow[t]{12}{*}{ Yellowfin } & 1 & 170 & $19-147.5$ & $\mathrm{~L}_{\infty}$ & 165.29 & 14.09 \\
\hline & & & & $\mathrm{k} 1$ & 0.211 & 0.044 \\
\hline & & & & k2 & 0.762 & 0.339 \\
\hline & & & & $\mathrm{t}_{0}$ & -0.469 & 0.248 \\
\hline & & & & $\alpha$ & 2.069 & 0.54 \\
\hline & & & & $\beta$ & 7.382 & 14.587 \\
\hline & 2 & 108 & 19-152 & $\mathrm{L}_{\infty}$ & 170.47 & 12.81 \\
\hline & & & & k1 & 0.188 & 0.04 \\
\hline & & & & k2 & 0.602 & 0.301 \\
\hline & & & & $\mathrm{t}_{0}$ & -0.593 & 0.291 \\
\hline & & & & $\alpha$ & 2.698 & 0.697 \\
\hline & & & & $\beta$ & 7.375 & 14.656 \\
\hline
\end{tabular}

\section{Supplementary references}

747 Borchani, A., 2010. Statistiques des valeurs extrêmes dans le cas de lois discrètes. Technical Report ESSEC Working Paper 10009, ESSEC Business School.

Gelman, A. and Rubin, D., 1992. Inference from iterative simulation using multiple sequences. Statistical Science, 7:457-511.

Laslett, G., Eveson, J., and Polacheck, T., 2002. A flexible maximum likelihood approach for fitting growth curves to tag-recapture data. Canadian Journal of Fisheries and Aquatic Sciences, 59:976-986. 
Spiegelhalter, D., Thomas, A., Best, N., and Lunn, D., 2011. OpenBUGS version 3.2.1 user manual. 